\title{
A Coupling Dynamics Analysis Method for Two-Stage Spur Gear under Multisource Time-Varying Excitation
}

\author{
Zizhen Qiao, ${ }^{1,2}$ Jianxing Zhou ${ }^{10},{ }^{1,2}$ Wenlei Sun, ${ }^{2}$ and Xiangfeng Zhang ${ }^{2}$ \\ ${ }^{1}$ State Key Laboratory of Mechanical Transmission, Chongqing University, Chongqing 400044, China \\ ${ }^{2}$ Xinjiang University, School of Mechanical Engineering, Urumqi 830047, China \\ Correspondence should be addressed to Jianxing Zhou; jianzhou82923@163.com
}

Received 21 June 2019; Revised 10 October 2019; Accepted 17 October 2019; Published 7 November 2019

Academic Editor: Vadim V. Silberschmidt

Copyright (c) 2019 Zizhen Qiao et al. This is an open access article distributed under the Creative Commons Attribution License, which permits unrestricted use, distribution, and reproduction in any medium, provided the original work is properly cited.

A new modeling method is proposed to simulate the dynamic response of a two-stage gear transmission system using the finite element method (FEM). The continuous system is divided into four modules: shaft-shaft element, shaft-gear element, shaft-bearing element, and gear-gear element. According to the FEM, the model is built with each element assembled. Meanwhile, the model considers the time-varying mesh stiffness (TVMS), bearing time-varying stiffness (BTVS), and the shaft flexibility. The Newmark integration method (NIM) is used to obtain the dynamic response of the spur gear system. Results show that vibration amplitude and the number of frequency components decrease after considering shaft flexibility through comparing the gear dynamic response under the condition of flexible shaft and rigid shaft. When the effect of bearing stiffness is considered, there will be a bearing passing frequency component in the frequency spectrum. In addition, the result shows that the simulation and experimental test of the frequency component are basically consistent. Furthermore, the theoretical model is validated against an experimental platform of the two-stage gear transmission system and the dynamic responses are compared under the condition of increasing speed. Additionally, the increase of shaft stiffness not only changes some of the dominant mode shapes (torsional mode shapes) but also makes the number of primary resonance speeds added. The method can be used to guide the design of gear systems.

\section{Introduction}

The gear transmission system has many advantages, such as high efficiency, compact structure, and stable transmission ratio, so it is one of the most important mechanical transmission methods $[1,2]$. Hence, it is extensively used in highspeed, large-power, and low-speed, high-torque applications, such as automotive transmissions, gas turbines, marine main reducers, tanks, engineering machinery, and 3D printers [3]. Sometimes, the complexity of the structure of the gear system, the time-varying stiffness, and other nonlinear factors can become an excitation source leading to premature failure of the transmission system [4]. For this reason, the coupled dynamic response of the gear system has recently become an important research topic. Currently, the lumped parameter method and finite element methods (FEM) are two common modeling approaches applied to the analysis of coupling vibration in the gear system [5]. Presently, the lumped parameter method applied to model multistage gear dynamics assumes that the gear, shaft, and bearing are concentrated points. Additionally, the complex coupling effect between the elastic shaft elements is represented with simple bending, torsional, and axial stiffness. These assumptions often render the lumped parameter models less accurate because they are not able to reliably distinguish between the shaft section and bearing and are not able to account for the geometrical dimensions of the shaft [6-10]. In contrast, the FEM has good calculation accuracy and is of greater importance for predicting the vibration noise of the system. In the literature, use of the FEM for calculating dynamic response has been reported by many researchers. Neriya and Sankar [11] introduced the FEM in the study of the dynamics of gear rotor systems and established the linear modeling of meshing stiffness. Modak et al. [12] updated a finite element model of a structure so that an updated model predicts more accurately the dynamics of a structure. With the development of the research, the coupling between parts has been considered, and the coupling model of the gear system has been established. 
ÖzgÜven and Özkan [13] established the dynamic model of a shaft-gear-bearing system to study the response of a coupled system. Ouyang et al. [14] investigated dynamic characteristics of gear-roller-bearing system by use of experimental test and theoretical modeling, and dynamic characteristics of gearroller-bearing system are investigated using of experimental test and theoretical modeling. Kubur et al. [15] established the dynamic model of a gear system with $N$ shafts and $N-1$ meshing pairs to study the relationship between the dynamic load of the bearing and the shaft length. Jiang et al. [16] established a complete mechanical model of rotor-gear system using both a lumped parameter model and a finite element model (shaft, gear, and rotor elements are modeled using the lumped parameter method and assembled with the FEM). Guo et al. [17] established a gear-bearing-housing system and investigated the vibration propagation of gear dynamics using mathematical modeling and finite element analysis. Ma et al. [18] studied the effects of varying amounts of profile relief on the mesh stiffness of a spur gear with FEM and substituted it into the dynamic model of the gear system. Jing et al. [4, 9] proposed a coupling dynamic method for a multistage planetary gear system and analyzed coupling vibration mechanism in the planetary gear system. Qian et al. [19] used finite element modeling to establish dynamic modeling of a single-stage gear transmission system considering the shaft, gear gyroscopic effects, and they calculated the natural characteristics of the system. Ankur et al. [20] established the shaft, bearing, and meshing gear pairs separately, and the viscous damping model is used to represent bearing and gear mesh damping. Wang [21] established a two-dimensional (2D) spur gear with FEM to calculate the static transmission error, single and combined torsional mesh stiffness, tooth load-sharing ratio, maximum tooth root stress, and surface contact stress against various input torques over a complete mesh cycle.

The bulk of existing literatures established the coupling dynamic modeling for a gear system, and the dynamic characteristics were studied to some extent. Few studies have established the two-stage spur gear system with FEM and conducted on the comprehensive influence of TVMS, BTVS and different shaft stiffness on the mode shape and the vibration transmission of the system simultaneously. This study considers the excitation of TVMS and BTVS as well as error excitation and also includes the flexibility of transmission shaft. Then, the FE modeling of the two-stage spur gear transmission system is established with FEM. The influence of different shaft stiffness on mode shape and dynamic response are analyzed. The amplitude and frequencyresponse curves of the vibration acceleration of the bearing are obtained with simulation and compared with the experimental results.

\section{Dynamic Model of Geared System}

The general gear system includes input/output system, transmission system consisting of gear shaft system, and structural system made up of bearing seats. The two-stage spur gear transmission system is shown in Figure 1.

The parameters of the system are shown in Tables 1 and 2.

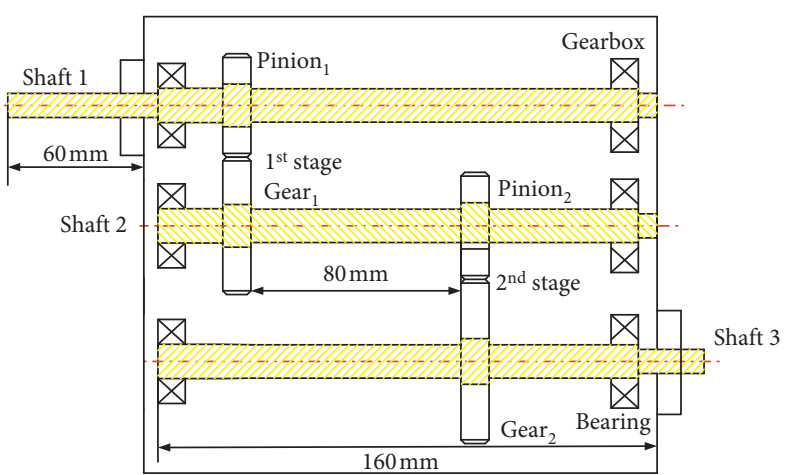

Figure 1: Structural model of two-stage gear transmission system (all dimensions are in $\mathrm{mm}$ ).

2.1. Coupling Model of Gear System. The gear transmission system is a continuous elastomer with countless degrees of freedom (DOFs). In order to accurately model the dynamic performance and efficiently understand the coupling vibration mechanism in the two-stage gear system, the FEM is put forward in this study. In the proposed approach, the system is divided into many elements.

Then, the FEM dynamic model of the two-stage gear transmission system is established, including the shaft, gear, and bearing elements, as shown in Figure 2. In this, the first shaft is divided into 12 elements, the second one 8 elements, and the third one 9 elements. Each element node is numbered. There are two rolling ball bearings on each shaft forming shaft-bearing coupling element. Furthermore, on the No. 7 node of the first shaft and the No. 16 node of the second shaft are the first-stage pinion and gear, respectively; on the No. 20 node of the second shaft and the No. 29 node of the third shaft are the second-stage pinion and gear, respectively. In this study, different nodes can realize physical connection and mechanical coupling of shaft-bearing, shaft-gear, and gear-gear through coupling. In the specific application, we can properly add the number of nodes at different shafting sections and divide more shafting elements according to the assembly requirements of shafts, the geometrical shape, practical accuracy requirements, and so on.

2.2. Shaft Element. The shaft is mainly for supporting rotation components and transmitting power, thus it is one of important parts in the gear transmission system [22]. The element models of elastic shafts are built in order to effectively consider shaft's deformation, as shown in Figure 3. Space beam element theory is used for force analysis, which is mainly Euler-Bernoulli beam theory or Timoshenko beam theory [23]. Based on Table 1, the width diameter of the shaft in this gear system modeling is quite small, and the shearing deformation should be considered; thus, Timoshenko beam theory can be used to analyze the shafting section elements.

As shown in Figure 3, every simple shaft can be divided into many elastic shafting elements. The length of the element is $l$, the elastic modulus is $E$, and the rotational 
TABle 1: Parameters of the transmission shaft.

\begin{tabular}{lccccc}
\hline Parameter & Length of shaft $(\mathrm{m})$ & Radius $(\mathrm{mm})$ & Density $\left(\mathrm{kg} / \mathrm{m}^{3}\right)$ & Elastic modulus $(\mathrm{Pa})$ & Shear modulus $(\mathrm{Pa})$ \\
\hline Shaft 1 & 0.24 & 10 & 7850 & $2.1 \times 10^{11}$ & $8 \times 10^{10}$ \\
Shaft 2 & 0.16 & 10 & 7850 & $2.1 \times 10^{11}$ & $8 \times 10^{10}$ \\
Shaft 3 & 0.18 & 10 & 7850 & $2.1 \times 10^{11}$ & $8 \times 10^{10}$ \\
\hline
\end{tabular}

TABLe 2: Parameters of the gear.

\begin{tabular}{lcccc}
\hline Parameter & Stage-I pinion & Stage-I gear & Stage-II pinion & Stage-II gear \\
\hline Rotary inertia $\left(\mathrm{kg} \cdot \mathrm{m}^{2}\right)$ & $2 \times 10^{-4}$ & $3.04 \times 10^{-3}$ & $1 \times 10^{-4}$ & 29 \\
Tooth number & 36 & 90 & 1.5 & 100 \\
Modulus $(\mathrm{mm})$ & 1.5 & 1.5 & 20 & 1.5 \\
Pressure angle $\left({ }^{\circ}\right)$ & 20 & 20 & 12 & 20 \\
Tooth width $(\mathrm{mm})$ & 12 & 12 & 0.09 & 12 \\
Mass $(\mathrm{kg})$ & 0.16 & 1.3 & & 1.6 \\
\hline
\end{tabular}

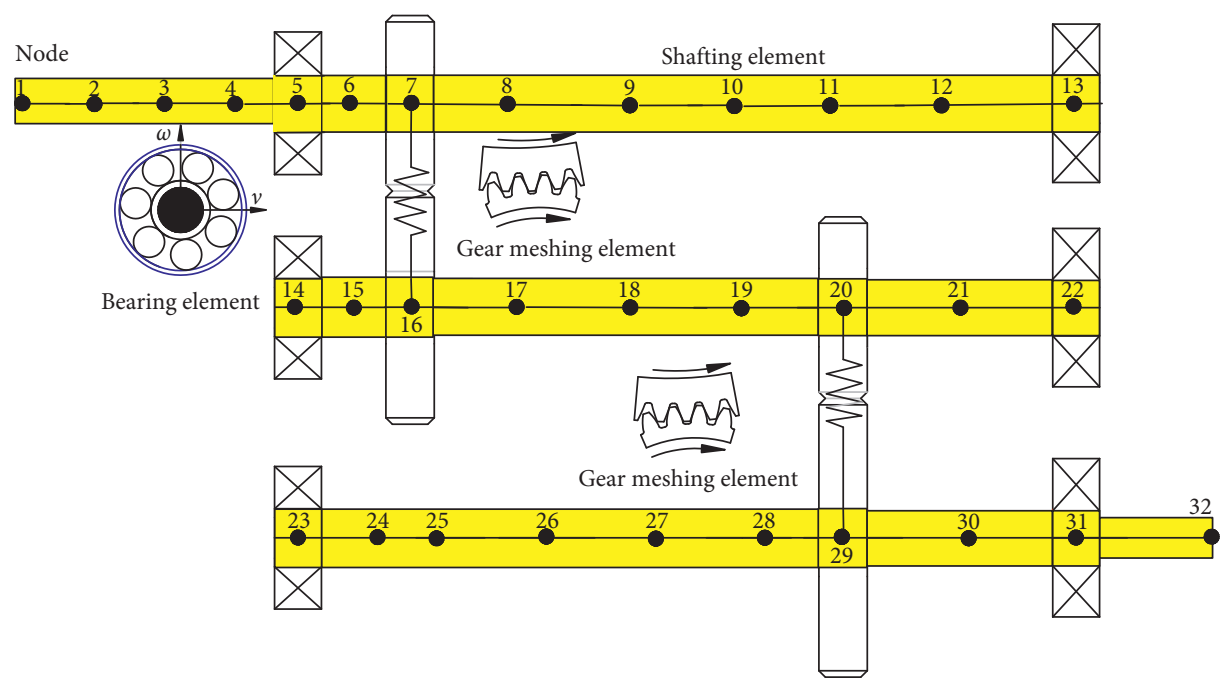

FIGURE 2: Finite element modeling of the two-stage gear transmission system.

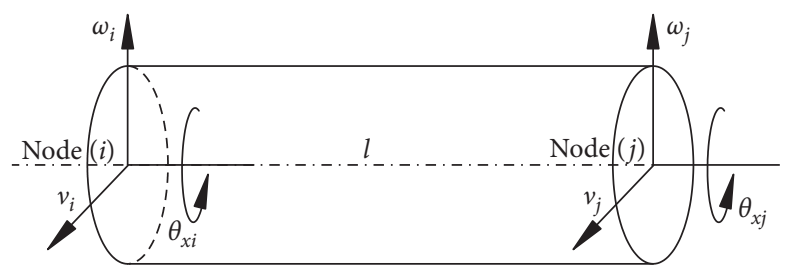

Figure 3: The finite element model of shafting element.

inertia is $J$. The two nodes of the shaft element are $i$ and $j$. Since this model is a parallel shaft spur gear transmission system, there is almost no excitation in the axial direction. Therefore, each node has been given three DOFs, and each node of the shaft has two translational DOFs and 1 torsional ones. The generalized coordinates of the shaft element are

$$
\{\delta\}^{e}=\left[\begin{array}{llllll}
v_{i} & \omega_{i} & \theta_{i} & v_{j} & \omega_{j} & \theta_{j}
\end{array}\right]^{T}
$$

where the subscripts indicate the shafting section, $v$ and $\omega$ are the translational DOFs, and $\theta$ is the torsional DOF. The stiffness matrix and the mass matrix of shafting element $6 \times 6$ are obtained as follows: 


$$
K^{e}=\left[\begin{array}{cccccc}
\frac{G A}{K l} & 0 & 0 & -\frac{G A}{K l} & 0 & 0 \\
0 & \frac{G A}{K l} & 0 & 0 & -\frac{G A}{K l} & 0 \\
0 & 0 & \frac{G J}{l} & 0 & 0 & -\frac{G J}{l} \\
-\frac{G A}{K l} & 0 & 0 & \frac{G A}{K l} & 0 & 0 \\
0 & -\frac{G A}{K l} & 0 & 0 & \frac{G A}{K l} & 0 \\
0 & 0 & -\frac{G J}{l} & 0 & 0 & \frac{G J}{l}
\end{array}\right] \text {, }
$$

$$
M^{e}=\frac{\rho A l}{6}\left[\begin{array}{cccccc}
2 & 0 & 0 & 1 & 0 & 0 \\
0 & 2 & 0 & 0 & 1 & 0 \\
0 & 0 & 2 \frac{J}{A} & 0 & 0 & -\frac{J}{A} \\
1 & 0 & 0 & 2 & 0 & 0 \\
0 & 1 & 0 & 0 & 2 & 0 \\
0 & 0 & \frac{J}{A} & 0 & 0 & 2 \frac{J}{A}
\end{array}\right] \text {. }
$$

Damping can also be added to the shaft model via Rayleigh damping as

$$
C_{\mathrm{m}}=\chi \cdot M_{\mathrm{S}}+\varphi \cdot K_{\mathrm{s}},
$$

where $M_{\mathrm{S}}$ and $K_{\mathrm{s}}$ denote mass matrix and stiffness matrix of shafting element and $\chi$ and $\varphi$ denote the scale factors. The specific calculating method can be referred to [24].

2.3. Mesh Element and Mesh Stiffness. The meshing action of the gears is equivalent to that of a spring and damper. For DOF analysis, besides the torsional vibration, other kinds of vibration should be taken into account, because there is almost no excitation in the axial direction for spur gear. It can be thought that there are transverse and torsional vibrations without axial DOF of the meshing elements. As

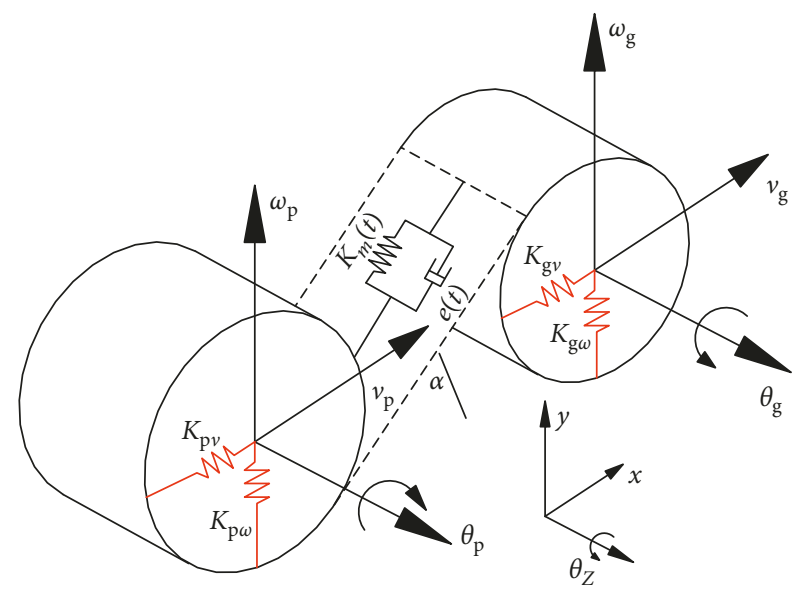

FIGURE 4: Meshing element.

shown in Figure 4, the dynamics model of gear meshing pair is established, where $\mathrm{p}$ and $\mathrm{g}$ are pinion and gear, $k_{\mathrm{m}}(t)$ is the TVMS of meshing elements, $v_{\mathrm{p}}, \omega_{\mathrm{p}}, \theta_{\mathrm{p}}, v_{\mathrm{g}}, \omega_{\mathrm{g}}$, and $\theta_{\mathrm{g}}$ denote the transverse vibration displacement and torsional angle of pinion and gear respectively, and $\alpha$ denotes the pressure angle.

The generalized coordinates of the meshing element can be expressed as

$$
\{X\}=\left\{\nu_{\mathrm{p}}, \omega_{\mathrm{p}}, \theta_{\mathrm{p}}, \nu_{\mathrm{g}}, \omega_{\mathrm{g}}, \theta_{\mathrm{g}}\right\}^{T} .
$$

The vibration of the gear along the torsional DOF and translational DOF can change the meshing of gear pairs. The projection vector of the displacement of freedom of the gear in the meshing line direction [25] can be expressed in the following equation.

$$
\left\{\begin{array}{l}
\bar{x}_{\mathrm{p}}=v_{\mathrm{p}} \sin \alpha+w_{\mathrm{p}} \cos \alpha-r_{\mathrm{p}} \theta_{\mathrm{p}}, \\
\bar{x}_{\mathrm{g}}=v_{\mathrm{g}} \sin \alpha+w_{\mathrm{g}} \cos \alpha+r_{\mathrm{g}} \theta_{\mathrm{g}}, \\
\bar{x}_{\mathrm{pg}}=v_{\mathrm{p}} \sin \alpha+w_{\mathrm{p}} \cos \alpha-r_{\mathrm{p}} \theta_{\mathrm{p}}-v_{\mathrm{g}} \sin \alpha-w_{\mathrm{g}} \cos \alpha-r_{\mathrm{g}} \theta_{\mathrm{g}},
\end{array}\right.
$$

where $r_{\mathrm{p}}$ and $r_{\mathrm{g}}$ denote the radius of pinion and gear.

The elastic meshing force of gear pair can be expressed in accordance with the following equation [25]:

$$
\begin{aligned}
F_{k}= & k_{\mathrm{m}} \cdot\left(v_{\mathrm{p}} \sin \alpha+\omega_{\mathrm{p}} \cos \alpha-r_{\mathrm{p}} \theta_{\mathrm{p}}-v_{\mathrm{g}} \sin \alpha-\omega_{\mathrm{p}} \cos \alpha\right. \\
& \left.-r_{\mathrm{g}} \theta_{\mathrm{g}}+e(t)\right),
\end{aligned}
$$

where $e(t)$ is the comprehensive error and $e(t)=e_{1}$ $\sin \left(2 \pi f_{\mathrm{m} 1} t\right)$, in this, $e_{1}$ denotes the error amplitude and $f_{\mathrm{m} 1}$ is the first-stage meshing frequency. The stiffness matrix of meshing pair [25] can be obtained as follows: 


$$
K_{\mathrm{m}}^{e}=\left[\begin{array}{cccccc}
k_{\mathrm{m}} \sin ^{2} \alpha & k_{\mathrm{m}} \cdot \sin \alpha \cos \alpha & -k_{\mathrm{m}} \cdot \sin \alpha \cdot r_{\mathrm{p}} & -k_{\mathrm{m}} \sin ^{2} \alpha & -k_{\mathrm{m}} \cdot \sin \alpha \cos \alpha & -k_{\mathrm{m}} \cdot \sin \alpha \cdot r_{\mathrm{g}} \\
k_{\mathrm{m}} \cdot \sin \alpha \cos \alpha & k_{\mathrm{m}} \cos ^{2} \alpha & -k_{\mathrm{m}} \cdot \cos \alpha \cdot r_{\mathrm{p}} & -k_{\mathrm{m}} \cdot \sin \alpha \cos \alpha & -k_{\mathrm{m}} \cos ^{2} \alpha & -k_{\mathrm{m}} \cdot \cos \alpha \cdot r_{\mathrm{g}} \\
-k_{\mathrm{m}} \cdot \sin \alpha \cdot r_{\mathrm{p}} & -k_{\mathrm{m}} \cdot \cos \alpha \cdot r_{\mathrm{p}} & -k_{\mathrm{m}} \cdot r_{\mathrm{p}}^{2} & k_{\mathrm{m}} \cdot \sin \alpha \cdot r_{\mathrm{p}} & k_{\mathrm{m}} \cdot \cos \alpha \cdot r_{\mathrm{p}} & k_{\mathrm{m}} \cdot r_{\mathrm{p}} \cdot r_{\mathrm{g}} \\
-k_{\mathrm{m}} \sin ^{2} \alpha & -k_{\mathrm{m}} \cdot \sin \alpha \cos \alpha & k_{\mathrm{m}} \cdot \sin \alpha \cdot r_{\mathrm{p}} & k_{\mathrm{m}} \sin ^{2} \alpha & k_{\mathrm{m}} \cdot \sin \alpha \cos \alpha & k_{\mathrm{m}} \cdot \sin \alpha \cdot r_{\mathrm{g}} \\
-k_{\mathrm{m}} \cdot \sin \alpha \cos \alpha & -k_{\mathrm{m}} \cos ^{2} \alpha & k_{\mathrm{m}} \cdot \cos \alpha \cdot r_{\mathrm{p}} & k_{\mathrm{m}} \cdot \sin \alpha \cos \alpha & k_{\mathrm{m}} \cos { }^{2} \alpha & k_{\mathrm{m}} \cdot \cos \alpha \cdot r_{\mathrm{g}} \\
-k_{\mathrm{m}} \cdot \sin \alpha \cdot r_{\mathrm{g}} & -k_{\mathrm{m}} \cdot \cos \alpha \cdot r_{\mathrm{g}} & k_{\mathrm{m}} \cdot r_{\mathrm{p}} \cdot r_{\mathrm{g}} & k_{\mathrm{m}} \cdot \sin \alpha \cdot r_{\mathrm{g}} & k_{\mathrm{m}} \cdot \cos \alpha \cdot r_{\mathrm{g}} & k_{\mathrm{m}} \cdot r_{\mathrm{g}}^{2}
\end{array}\right] .
$$

The finite element method was adopted to calculate the mesh stiffness of several meshing positions within a meshing period. In application of boundary condition, the gear is subjected to full constraint, the radial and axial constraint is applied to the pinion, and the unit force is applied to the circumferential node to solve, as shown in Figure 5(a). The gear pair appears deformed to a certain extent under the action of external load, and the pinion appears a small rotation angle. The microangle $\theta$ of the pinion can be expressed as

$$
\theta=\frac{\delta_{\mathrm{g}}}{r_{1}}
$$

where $\delta_{\mathrm{g}}$ is the mean value of gear tooth deformation and $r_{1}$ is the radius of the inner ring gear of the pinion.

The small deformation of the inner ring of the pinion can be converted into the deformation of the contact gear tooth with the relationship between the small rotation angle and the radius of the base circle. The mesh deformation $\delta_{\mathrm{s}}$ can be defined as

$$
\delta_{\mathrm{s}}=\theta \times r_{\mathrm{b}},
$$

where $r_{\mathrm{b}}$ is the radius of the base circle of the pinion.

Through the relationship between the unit force applied by the inner ring node of the pinion and the radius of the inner ring and the radius of the base circle of the pinion, the node load applied to the inner ring of the pinion is converted into the mesh force of the gear teeth. The meshing force $F_{n}$ can be expressed from the following equation:

$$
F_{n}=\frac{n r_{1}}{r_{\mathrm{b}}},
$$

where $n$ is the number of inner ring nodes.

Finally, the stiffness can be expressed as follows [26]:

$$
K_{n}=\frac{n r_{1}^{2}}{\delta_{\mathrm{g}} r_{\mathrm{b}}^{2}}
$$

The mesh stiffness curve of the gear teeth from mesh to mesh (one mesh period) is obtained with FEM as shown in Figure 5.

2.4. Bearing Element and Bearing Stiffness. Bearing is mainly to support the shaft system and connect to shaft system and box. The stiffness of rolling bearing is time-varying under complicated working conditions of high rotating speed and varying loads. Since the model is a rolling ball bearing and there is almost no excitation in the axial direction, the model of deep groove ball bearing model and two bearing loading forms are shown in Figure 6 [27].

The stiffness matrix of bearing can be obtained as follows:

$$
K_{\mathrm{m}}^{e}=\operatorname{diag}\left(k_{\mathrm{b} v}, k_{\mathrm{b} \omega}, 0\right) .
$$

Usually, the form of motion of the bearing has two situations. One is shown in Figure 6(b) - radial load falling on the lowest roller bearing (odd pressure); the other is shown in Figure 6(c) - radial load falling between the two lowest roller bearings (even pressure). The curvature sum and subtraction of bearings are obtained from the previous work [25]. Table 3 gives the basic parameters of the bearing and the calculated numerical number.

For inner race contact, the contact displacement is $\delta_{1}=0.59$, and for outer race contact, it is $\delta_{0}=0.66$ [24]. The load-displacement coefficient during point contact can be expressed as

$$
k_{\mathrm{p}}=2.15 \times 10^{5} \sum \rho^{-1 / 2}(\delta)^{-3 / 2} .
$$

Then, we can obtain the load-displacement coefficients of inner and outer race contacts, respectively.

The load-displacement coefficient of normal load direction is as follows:

$$
k_{n}=\left(k_{\mathrm{pi}}^{-1 / 1.5}+k_{\mathrm{po}}^{-1 / 1.5}\right) .
$$

Radius displacement of bearing can be calculated in the following equation:

$$
Q_{\delta_{\mathrm{r}}}=4.36 \times 10^{-4} \frac{Q_{\max }^{2 / 3}}{D^{1 / 3} \cos \alpha_{\max }},
$$

where $Q_{\max }$ denotes the maximum normal load, $D$ denotes the diameter of bearing race, and $\alpha_{0}$ denotes the contact angle of deep groove ball bearing.

Bearing stiffness for odd pressure can be expressed as

$$
k_{\mathrm{bo}}=\frac{F_{\mathrm{r}}}{\delta_{\mathrm{r}}}
$$

where $\mathrm{F}_{\mathrm{r}}$ is the radial load.

Under even pressure, there is no direct force on the rollers with the influence of the radial load. Take the load of $\psi= \pm 22.5^{\circ}$ as the maximum load of rolling element to get the bearing stiffness under even pressure. Thereby, the stiffness under even pressure and odd pressure can be obtained. They can be expressed as follows: $k_{\mathrm{be}}=8.95 \times 10^{8} \mathrm{~N} / \mathrm{m}$ and $k_{\mathrm{bo}}=8.21 \times 10^{8} \mathrm{~N} / \mathrm{m}$. Hence, the time-varying stiffness is expressed as 


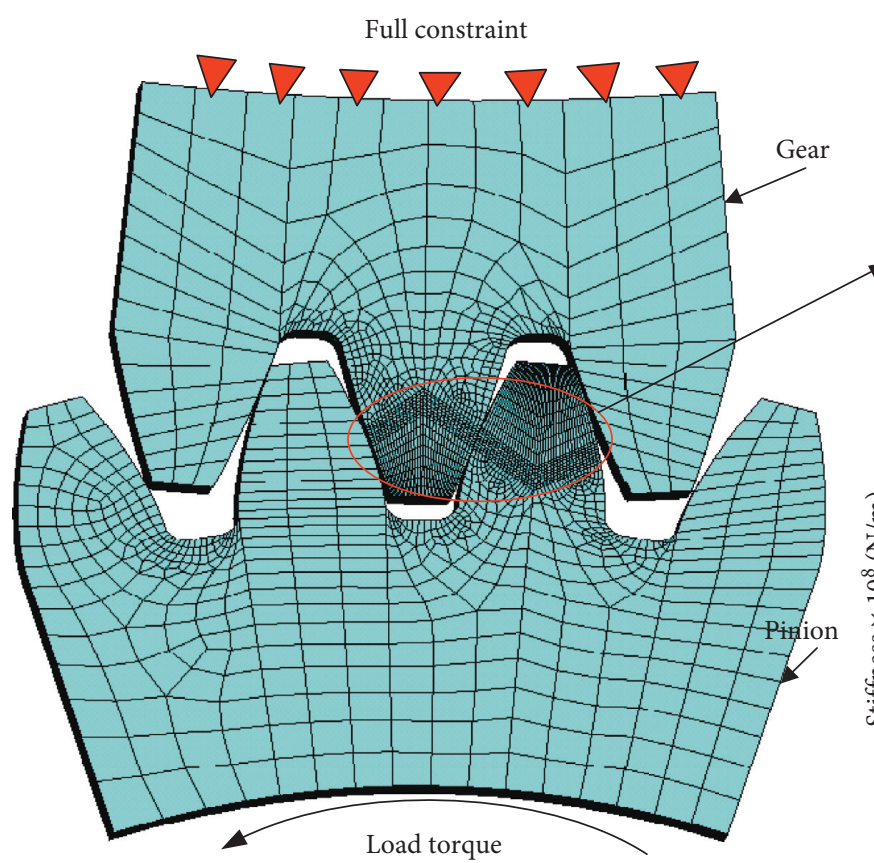

(a)

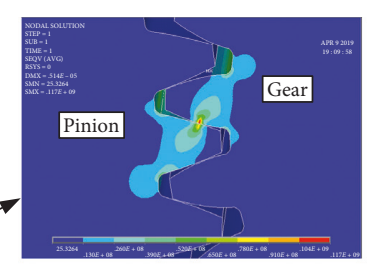

Single tooth meshing

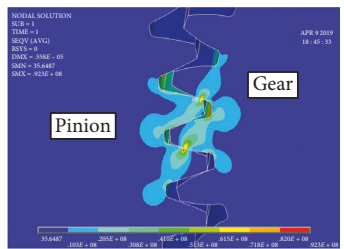

Douple tooth meshing

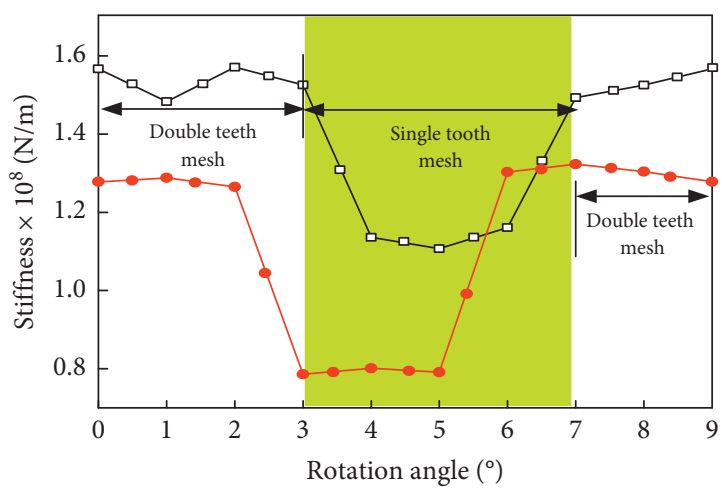

$\rightarrow 1^{\text {st }}$ stage

(b)

FIGURE 5: Solution of time-varying mesh stiffness. (a) FE analysis model of gear pair. (b) Meshing stiffness curve.

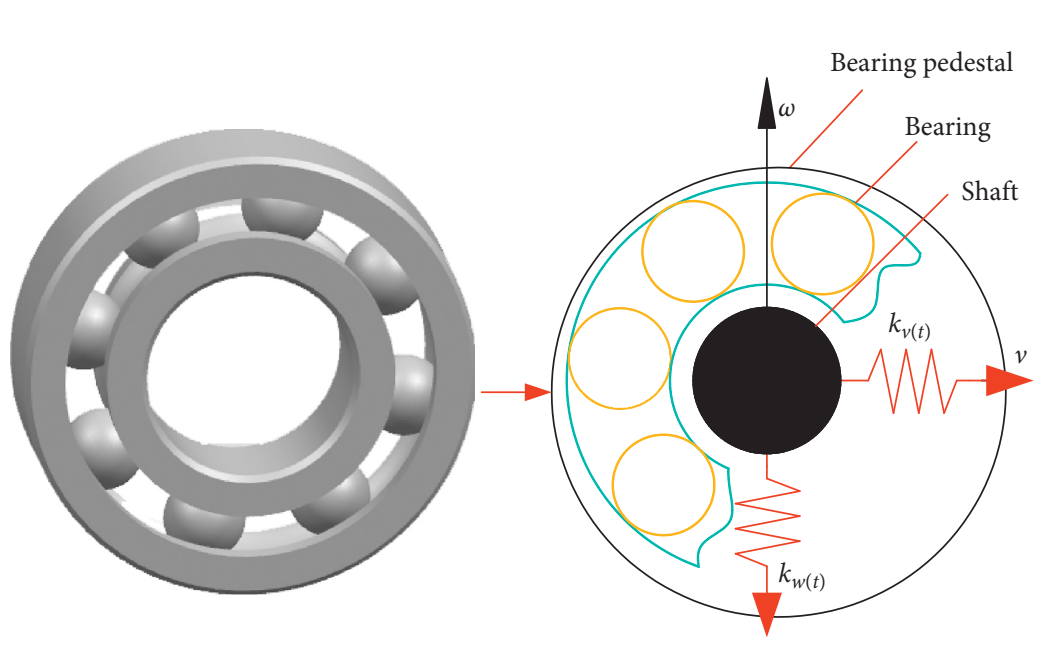

(a)

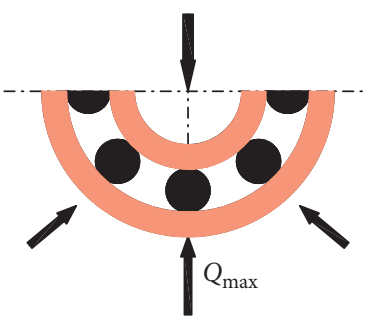

(b)

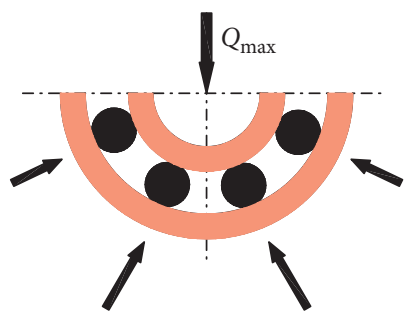

(c)

Figure 6: The dynamics model of deep groove ball bearing and two bearing forms. (a) The dynamics model of deep groove ball bearing. (b) Odd pressure state. (c) Occasional pressure state.

$$
k_{\mathrm{b}}(t)=k_{\mathrm{bs}}+k_{\mathrm{a}} \sin \left(2 \pi f_{\mathrm{b}} t+\beta_{\mathrm{b}}\right),
$$

where $k_{\mathrm{bs}}$ and $k_{\mathrm{a}}$ denote the static bearing stiffness and the waving amplitude of time-varying stiffness respectively and $\beta_{b}$ denotes the bearing passing frequency and the initial phase angle of bearing. Meanwhile, $k_{\mathrm{bs}}=\left(k_{\mathrm{b} 0}+k_{\mathrm{be}}\right) / 2$.

\section{System Model}

3.1. Two-Stage Phase Relationship. In order to establish twostage gear pair modeling and determine the two-stage phase relationship, firstly a coordinate system is established as shown in Figure 7. It is assume that $v_{\mathrm{p} 1}$ is theoretical central 
TABLE 3: Bearing basic parameters.

\begin{tabular}{|c|c|c|c|c|}
\hline $\begin{array}{l}\text { Diameter of inner race } \\
(\mathrm{mm})\end{array}$ & $\begin{array}{l}\text { Diameter of outer race } \\
(\mathrm{mm})\end{array}$ & $\begin{array}{l}\text { Ball diameter } \\
(\mathrm{mm})\end{array}$ & $\begin{array}{c}\text { Curvature radius of inner and outer } \\
\text { grooves }(\mathrm{mm})\end{array}$ & Ball number \\
\hline 28.7 & 46.6 & 8.7 & 45 & 8 \\
\hline $\begin{array}{l}\text { Pitch circle diameter } \\
(\mathrm{mm})\end{array}$ & $\begin{array}{l}\text { Radial internal } \\
\text { clearance }\end{array}$ & Goodness fit & Curvature sum inner/outer & $\begin{array}{c}\text { Curvature subtraction } \\
\text { inner/outer }\end{array}$ \\
\hline 37.65 & 0.5 & 0.5172 & $0.3078 / 0.1956$ & $0.9426 / 0.9095$ \\
\hline
\end{tabular}

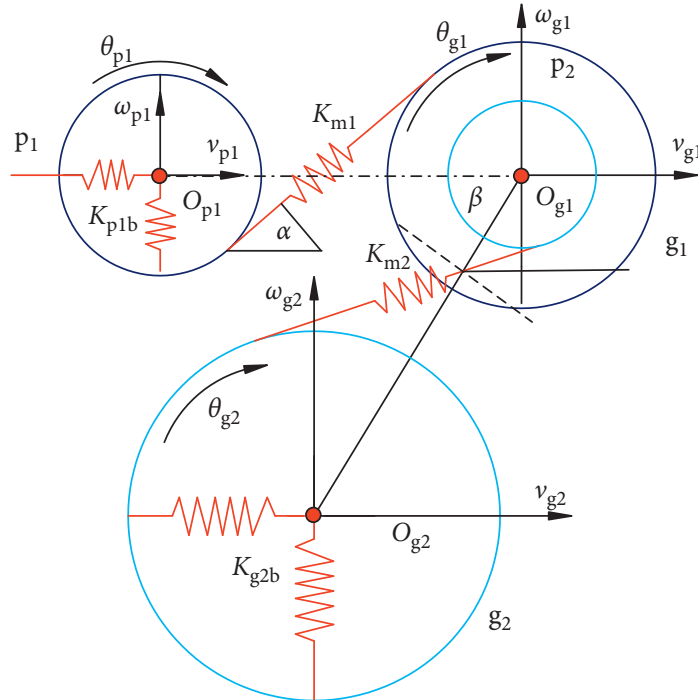

Figure 7: Two-stage phase relationship of the two-stage gear transmission system.

line of the first-stage gears and $w_{\mathrm{P} 1}$ is vertical to the central line of those two gears.

In the two-stage parallel shaft spur gear system, there is a translational vibration with no vibration in the axis, as shown in Figure 7 , where $v_{\mathrm{p} 1}, \omega_{\mathrm{p} 1}, \theta_{\mathrm{p} 1}, v_{\mathrm{g} 1}, \omega_{\mathrm{g} 1}$, and $\theta_{\mathrm{g} 1}$ are the translational vibration displacement and torsional angle of the first-stage pinion and gear, $v_{\mathrm{p} 2}, \omega_{\mathrm{p} 2}, \theta_{\mathrm{p} 2}, v_{\mathrm{g} 2}, \omega_{\mathrm{g} 2}$, and $\theta_{\mathrm{g} 2}$ are the translational vibration displacement and torsional angle of the second stage pinion and gear, $\alpha$ is the gear pressure angle, $\beta$ is the shaft intersection angle among three shafts. According to the geometrical relationship, the intersection angle between the second stage gear meshing line and $v_{\mathrm{p} 1}$ is reformulated as follows:

$$
\alpha_{2}=\beta-\left(\frac{\pi}{2-\alpha}\right) \text {. }
$$

Therefore, in the second stage gear system, the projection displacement vector in the direction of meshing line can be expressed in accordance with the following equation [28]:

$$
\left\{\begin{aligned}
\bar{x}_{\mathrm{p} 2}= & v_{\mathrm{p} 2} \sin \alpha_{2}+w_{\mathrm{p} 2} \cos \alpha_{2}-r_{\mathrm{p} 2} \theta_{\mathrm{p} 2} \\
\bar{x}_{\mathrm{g} 2}= & v_{\mathrm{g} 2} \sin \alpha_{2}+w_{\mathrm{g} 2} \cos \alpha_{2}+r_{\mathrm{g} 2} \theta_{\mathrm{g} 2} \\
\bar{x}_{\mathrm{p} 2 \mathrm{~g} 2}= & \bar{x}_{\mathrm{p} 2}-\bar{x}_{\mathrm{g} 2}=v_{\mathrm{p} 2} \sin \alpha_{2}+w_{\mathrm{p} 2} \cos \alpha_{2}-r_{\mathrm{p} 2} \theta_{\mathrm{p} 2} \\
& -v_{\mathrm{g} 2} \sin \alpha_{2}-w_{\mathrm{g} 2} \cos \alpha_{2}-r_{\mathrm{g} 2} \theta_{\mathrm{g} 2}
\end{aligned}\right.
$$

Meshing force of gear pair can be written as follows [28]:

$$
\begin{aligned}
F_{k}= & k_{\mathrm{m} 2} \cdot\left(v_{\mathrm{p} 2} \sin \alpha_{2}+\omega_{\mathrm{p} 2} \cos \alpha_{2}-r_{\mathrm{p} 2} \theta_{\mathrm{p} 2}-v_{\mathrm{g} 2} \sin \alpha_{2}\right. \\
& \left.-\omega_{\mathrm{p} 2} \cos \alpha_{2}-r_{\mathrm{g} 2} \theta_{\mathrm{g} 2}+e(t)\right),
\end{aligned}
$$

where $r_{\mathrm{p} 2}$ and $r_{\mathrm{g} 2}$ are the radii of base circle of pinion and gear in the second-stage transmission system, respectively, $k_{\mathrm{m} 2}(t)$ is the TVMS of second stage gear, $e_{2}(t)$ is the comprehensive error, further explanation, $e_{2}(t)=e_{2}$ $\sin \left(2 \pi f_{\mathrm{m} 2} t\right)$, where $e_{2}$ denotes the error amplitude, and in this, $f_{\mathrm{m} 2}$ is the second-stage gear meshing frequency.

3.2. Overall System Model. According to the physical quantities of stiffness matrix, mass matrix, load vector, and so on, the elements are assembled with the FEM. More specifically, the stiffness matrix of each element is sent into the overall stiffness matrix $[K]$ according to the assembly rules of the overall system. The generalized displacement vector of the system is as follows:

$\{x\}=\left\{x_{1 x}, x_{1 y}, x_{1 \theta}, x_{2 x}, x_{2 y}, x_{2 \theta}, \ldots \ldots, x_{n x}, x_{n y}, x_{n \theta}\right\}$ where $n$ is the number of nodes, $n=1,2, \ldots, 32$. The twostage gear transmission system with three shafts, six bearings, and two gear pairs is divided into 29 elements and 95 DOFs with the FEM under the boundary conditions (the No. 1 node connects with input end and it is subjected to a torsional DOF constraint, and the last node bears load torque).

The overall stiffness matrix assembly of the two-stage gear transmission system is shown in Figure 8, and the dynamic equations of the spur gear system can be expressed in accordance with equation (21).

$$
[m]\{\ddot{x}(t)\}+[c]\{\dot{x}(t)\}+[k(t)]\{x(t)\}=\{F(t)\},
$$

where $\{x(t)\}$ denotes the node displacement vector and $\{F(t)\}$ are the total mass, Rayleigh damping, stiffness matrix, and force vectors, respectively.

Dynamic calculation is done at last. Because stiffness matrix and displacement vector are periodic functions of time, they need to be calculated with the numerical integration. NIM has the format of unconditional stability with the adjusted parameters constant. It is verified that the calculation error and calculation are both less than the Cotes integration method, and the calculation efficiency is better than the traditional numerical method through tests [27]. Therefore, NIM can be used to analyze the dynamic response. 


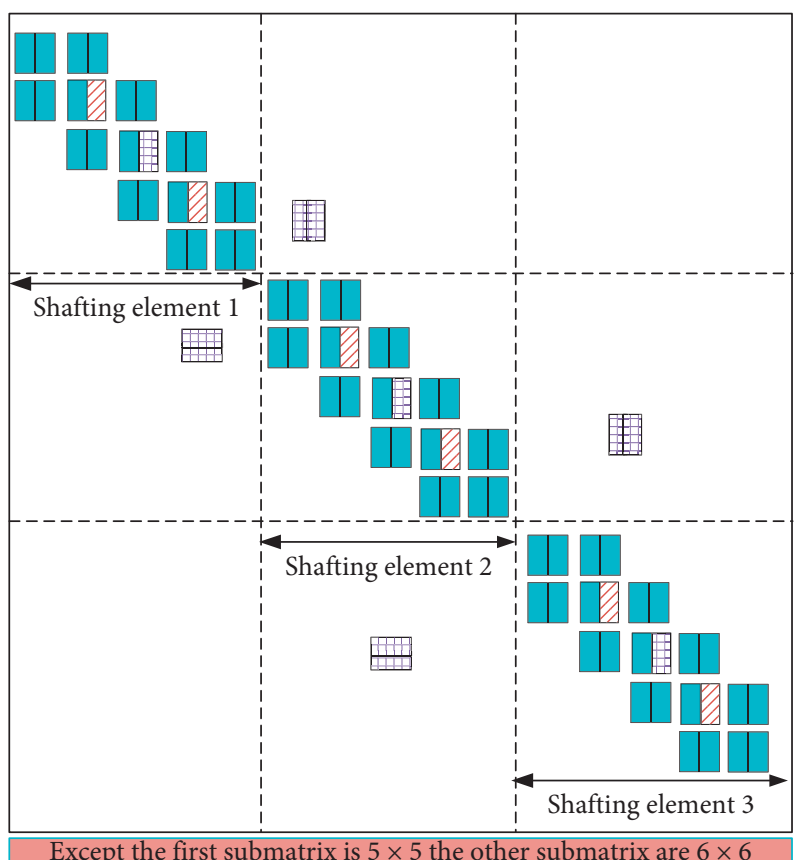

Except the first submatrix is $5 \times 5$ the other submatrix are $6 \times 6$

Shaft element submatrix

Shaft-gear submatrix

Shaft-bearing submatrix

Gear coupling submatrix

Figure 8: Schematic of the assembly rules of the overall system.

\section{Static Characteristic Analysis}

4.1. Transmission Shaft Deformation Analysis. Under loads, all the transmission shafts will bear the bending moment and torque produced by the gear's peripheral force and radial force, so deformation is inevitable. If the inertial force and damping force of the shafting element are not considered, the force of gear shaft can be analyzed based on statics. The deformation of shaft can be defined through load and transmission shaft's overall stiffness matrix. Therefore, the deformation $\left[\delta_{S}\right]$ can be solved with the following equation:

$$
\left[\delta_{\mathrm{S}}\right]=\frac{F}{\left[k_{\mathrm{s}}\right]}
$$

where $k_{\mathrm{s}}$ is the overall stiffness matrix of the shaft and $F$ is the force of shaft.

The deformation of gear shaft is shown in Figure 9 (compared with the actual results, it is amplified by $10^{5}$ times), under a constant input speed of $500 \mathrm{rpm}$ and a constant load of $100 \mathrm{~N} \cdot \mathrm{m}$ with simulation. The shaft couples bearing support and meshing gear pair. It is supposed that the maximum deformation of each shaft is $\left[\delta_{S}\right]$ and the first shaft has the maximum force at the No. 7 coupling node of the gear, with the maximum deformation of $0.55 \mu \mathrm{m}$; the second stage gear has small rotated speed and large load, so compared with the first-stage transmission shaft, it has larger deformation at the gear coupling position. The second transmission shaft has the maximum deformation of $1.98 \mu \mathrm{m}$ at the No. 20 node; the third transmission shaft has the maximum deformation of $1.70 \mu \mathrm{m}$ at the No. 29 node.

4.2. Static Transmission Error Analysis. The concept of transmission error was put forward by Harris [29] in 1958. It is defined as the active rotation over a certain angle of the pinion, the difference between the actual rotation angle and the theoretical rotation angle of the gear. If the gear has small rotated speed, the transmission error can be calculated based on static questions $[30,31]$. In this study, the static transmission error (STE) is simulated. The STEs of the gears are, respectively, expressed as

$$
\left\{\begin{array}{l}
\operatorname{STE}_{1}=\left(x_{18} \sin \alpha_{1}+x_{19} \cos \alpha_{1}-r_{\mathrm{p} 1} x_{20}-x_{45} \sin \alpha_{1}-x_{46} \cos \alpha_{1}-r_{\mathrm{g} 1} x_{47}\right) \\
\mathrm{STE}_{2}=\left(x_{57} \sin { }_{\alpha 2}+x_{58} \cos _{\alpha 2}-r_{\mathrm{p} 2} x_{59}-x_{84} \sin _{\alpha 2}-x_{85} \cos _{\alpha 2}-r_{\mathrm{g} 2} x_{86}\right)
\end{array}\right.
$$

where $x_{n}(n=18,19,20,45,46,47,57,58,59,85,86)$ is the displacement vector at the $n$th DOF.

The calculation result is shown in Figure 10. It can be found that in the process of single and double tooth alternation, because of the gear change of meshing stiffness, the STE will have great fluctuating changes. Compared with other positions, the STE has stable changes.

\section{Modal Analysis}

Without outer excitation of the system, the equation of free vibration can be obtained from formula (21) as follows:

$$
[m]\{\ddot{x}\}+[c]\{\dot{x}\}+[k]\{x\}=0 .
$$

During modal analysis, the damping exerts little influence on the natural frequency and mode shape of the gear system, so the damping can be neglected. Without considering the damping effect, the vibration equation of the system can be expressed as

$$
[m]\{\ddot{x}\}+[k]\{x\}=0 .
$$
follows:

The eigenvalues of the system can be expressed as

$$
\left(\bar{k}-w_{i}^{2} m\right) \varphi_{i}=0,
$$

where $\bar{k}$ is the average value of system stiffness and $w_{i}$ and $\varphi_{i}$ denote the natural frequency and mode shape of the system at $i^{\text {th }}$ order, respectively. The characteristic equation can be written as

$$
\bar{k}-w_{i}^{2} m=0 .
$$

Finally, the natural frequency and mode shapes of the system with the influence of the flexible shaft can be obtained. The system has natural frequency of 95 orders in total, and the first 20 orders natural frequencies are shown in Table 4. 


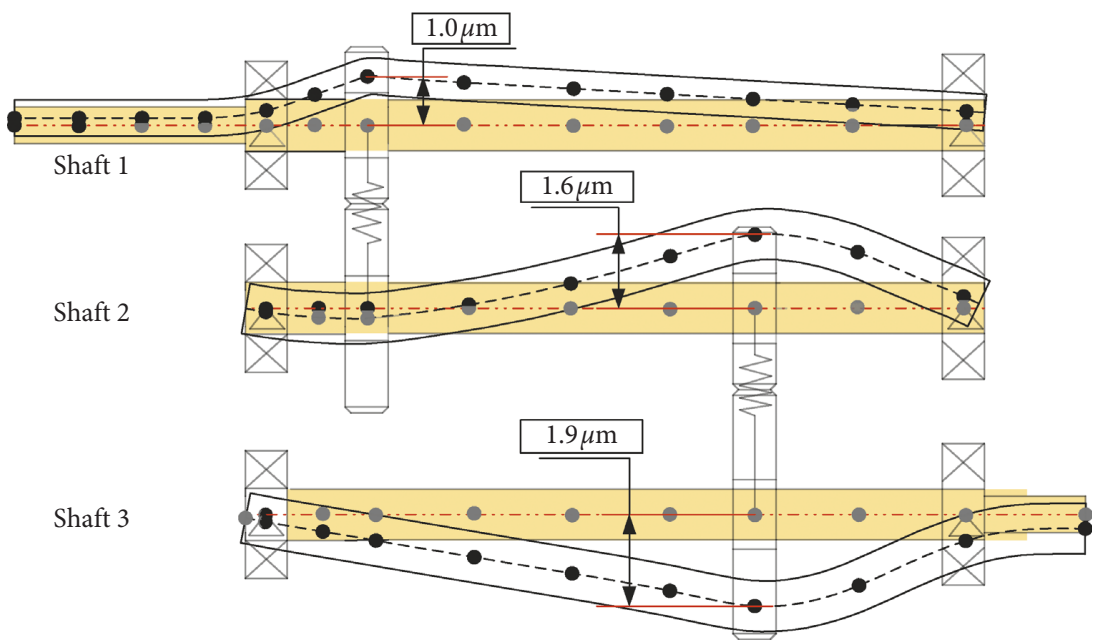

Figure 9: Schematic before and after deformation of transmission shaft.

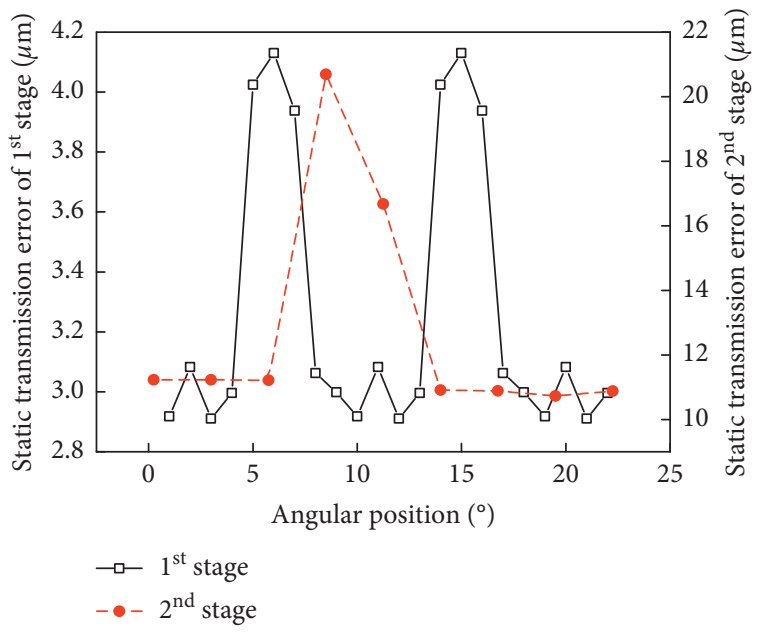

FIgURE 10: Static transmission error of gear.

The continuous system is divided into shaft-shaft, shaftgear, and other basic elements. The influence of geometric dimension and transmission shaft flexibility is considered to the model as described in Section 2.2. This section studies the effect of FE modeling with shaft flexibility on the coupling mode shapes of two-stage gear transmission system consisting of the torsion modes of gear pair, translational vibration, and bending modes of the transmission shaft through simulation. Owing to the effect of transmission shaft's flexibility, the transmission shafts show high-order bending mode shapes. The typical mode shapes are shown in Figure 11. The dominant vibration of the first order is torsional vibration of the first gear pair. The dominant vibration of third order is torsional vibration of the second stage gear. It has different vibration directions from torsional vibration of the first order, as shown in Figures 11(a) and 11(b) which show that the dominant vibration of the second order and fourth-order are translational vibrations of the gear; the dominant mode of sixth order and ninth order is low-order bending mode shape of the shaft, as shown in Figure 11(c). For the sixth-order mode shape, the shaft 1 and shaft 3 have concave bending vibration, and shaft 2 has convex ones; the three shafts at ninth order have convex vibration shape; because of the flexibility of transmission shaft, there are high-order bending mode shapes, as shown in Figure 11(d).

Consequently, the traditional lumped-mass model simplifies the transmission shaft into elastic elements of torsional and bending deformation. In modal analysis, the torsional mode shape and translational mode shape of the gear pair can only be analyzed, but the complex mode changes of the transmission shaft cannot be shown. Therefore, the FEM is used to optimize the modeling of twostage gear transmission and modify the gear structure to reanalyze its natural frequencies and the mode shapes. So, the method can be used for further studies.

\section{Dynamic Characteristic Simulation Analysis}

6.1. The Effect of Shaft Flexibility. Based on the two-stage gear system proposed in Section 2, the system dynamic responses can be calculated with Newmark integration method. The curves of the dynamic meshing force and frequency spectrum are shown in Figures 12 and 13 under a constant input speed of $500 \mathrm{rpm}$ and a constant load of $100 \mathrm{~N} \cdot \mathrm{m}$. It can be clearly found that the dynamic response of the gear has periodic stable signals with no amplitude modulation. Because of small rotating speed but large load of the second stage gear, its dynamic load vibration amplitude is rather larger than that of the first-stage gear. The major composition of the frequency spectrum is meshing frequency and its frequency multiplication $\left(f_{\mathrm{ml}}=\left(w_{1}\right.\right.$ $\left.\left.\times Z_{\mathrm{P} 1}\right) / 2 \pi, f_{\mathrm{m} 2}=\left(\left(w_{1} \times Z_{\mathrm{P} 1}\right) /\left(2 \pi \times Z_{\mathrm{g} 1}\right)\right) Z_{\mathrm{p} 2}\right)$. Meanwhile, there is a natural frequency $\left(f_{n 1}=128 \mathrm{~Hz}\right)$ at low-frequency stage.

Although the coefficient of the Fourier series reduced with the increase of harmonics order, because of the influence of frequency-response function and nonlinear feedback which makes the vibration energy of the system not strictly obey the change law [32]. In the first-stage gear system, the maximum amplitude frequency component is $f_{\mathrm{m} 1}$. In the second-stage gear system, the peak amplitude is 
TABLE 4: Natural frequencies of the system for the first 20 orders.

\begin{tabular}{|c|c|c|c|c|c|c|c|c|c|c|}
\hline Mode number & 1 & 2 & 3 & 4 & 5 & 6 & 7 & 8 & 9 & 10 \\
\hline Frequency $(\mathrm{Hz})$ & 128 & 205 & 1483 & 1595 & 1603 & 1760 & 2908 & 3231 & 4587 & 6484 \\
\hline Mode number & 11 & 12 & 13 & 14 & 15 & 16 & 17 & 18 & 19 & 20 \\
\hline Frequency $(\mathrm{Hz})$ & 6689 & 6691 & 8371 & 8805 & 8927 & 8948 & 12183 & 12185 & 12723 & 12842 \\
\hline
\end{tabular}
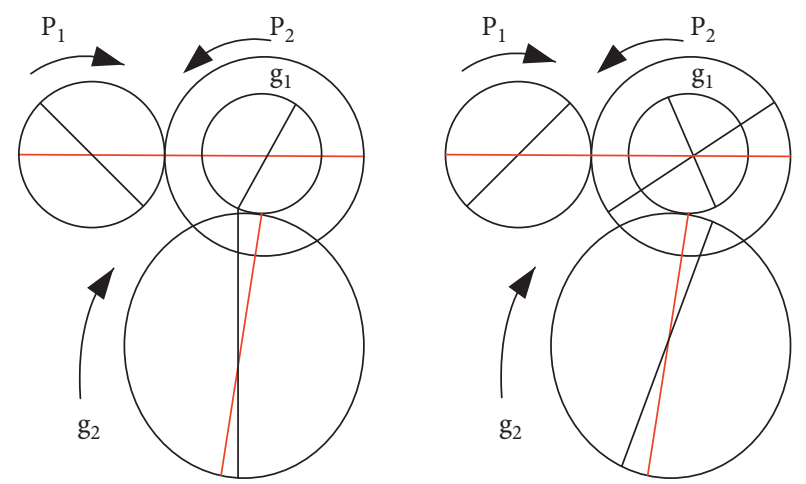

(a)

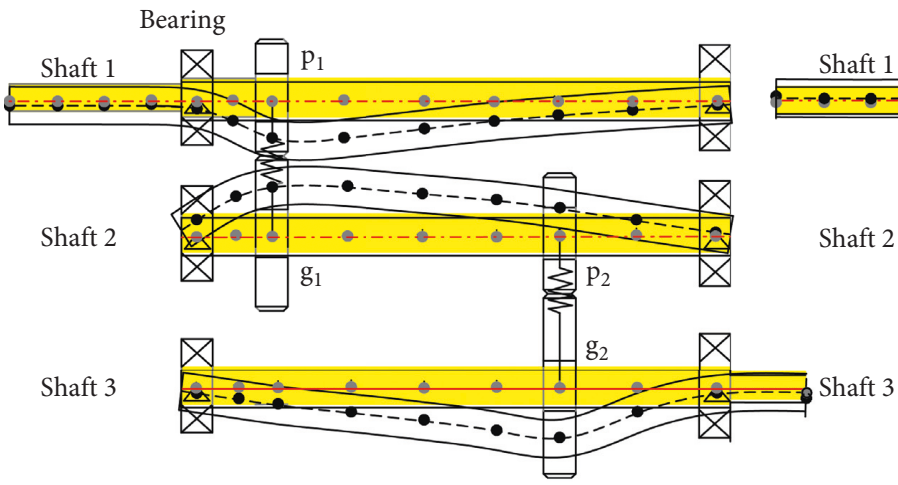

(c)

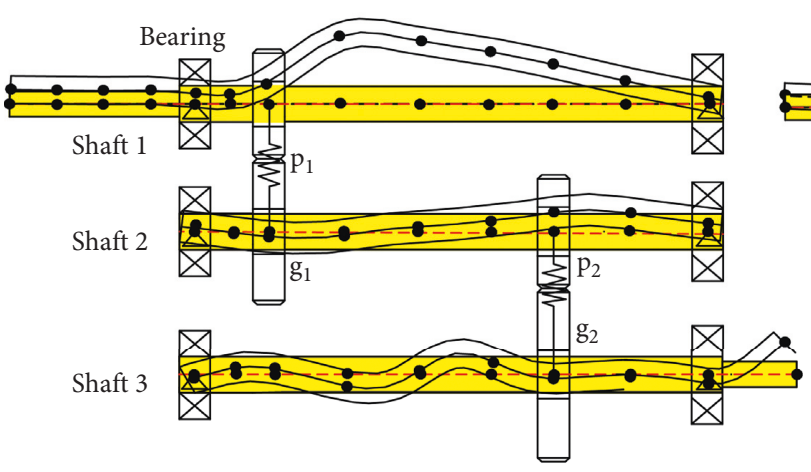

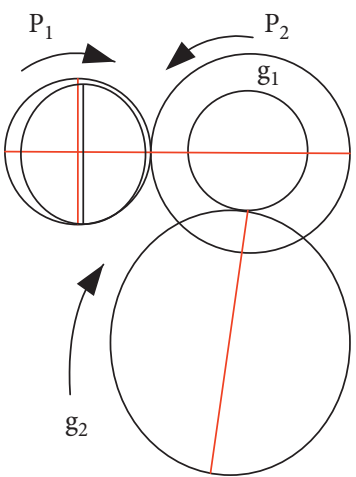

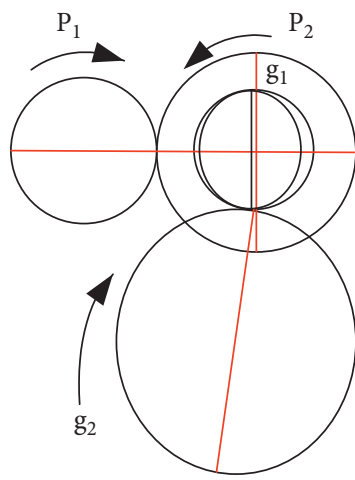

(b)

Bearing

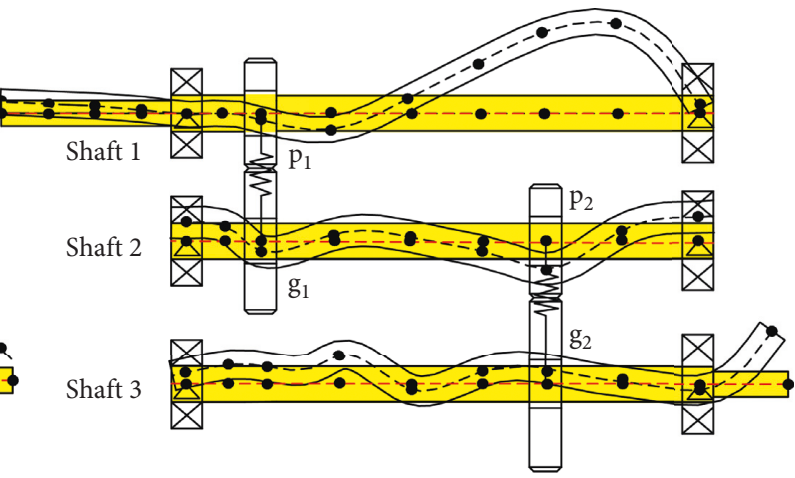

(d)

Figure 11: Mode shapes of the gear transmission system. (a) Torsional mode shapes of the coupling gear. (b) Transverse mode shapes of the coupling gear. (c) First-order bending mode shapes of the shaft. (d) Higher-order bending mode shapes of the shaft.

$2 f_{\mathrm{m} 2}$. This is because the frequency component of $2 f_{\mathrm{m} 2}$ is similar to the natural frequency of the second order and intensifies the vibration.

Next, the effect of the shaft flexibility on the system dynamic response is described. If the flexibility of shaft (elastic modulus: $E=2.1 \times 10^{11} \mathrm{~Pa}$ ) is considered, the maximum dynamic load decreases, the shock vibration of the dynamic load of the two-stage gears will greatly reduce, and the response signals are more stable compared with the timedomain process. The analysis of the frequency domain shows that, if the transmission shaft is considered a stiff body (elastic modulus: $E=2.1 \times 10^{12} \mathrm{~Pa}$ ), it shows a greater frequency signal, such as the natural amplitudes of the first order $\left(f_{n 1}\right)$, and $f_{\mathrm{m} 1}$ as well as its harmonics $\left(2 f_{\mathrm{m} 1}, 3 f_{\mathrm{m} 1}\right.$, etc $)$ and $2 f_{\mathrm{m} 2}, 5 f_{\mathrm{m} 2}, 7 f_{\mathrm{m} 2}$, and so on. In this, the peak amplitude of $f_{\mathrm{m} 1}$ is the largest. In summary, the dynamic load amplitude 


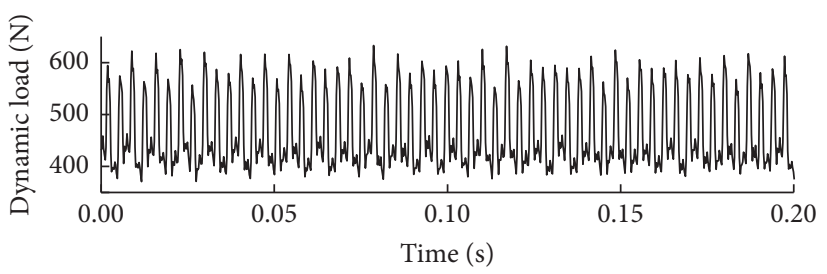

(a)

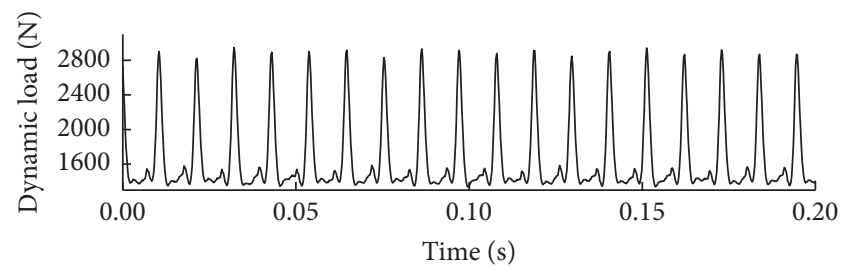

(c)

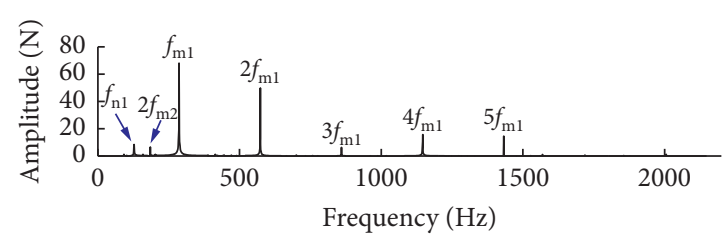

(b)

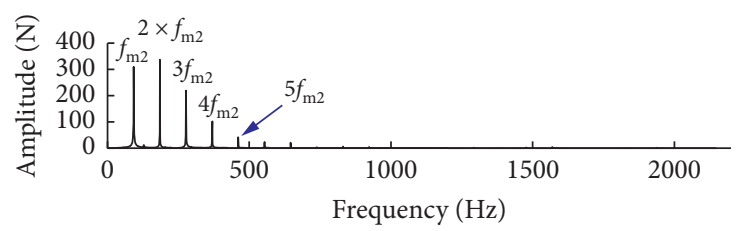

(d)

Figure 12: Dynamic load of the two-stage gear transmission system with flexible shaft. Dynamic load time history of (a) the first gear and (c) the second gear. Dynamic load spectrum history of (b) the first gear and (d) the second gear.

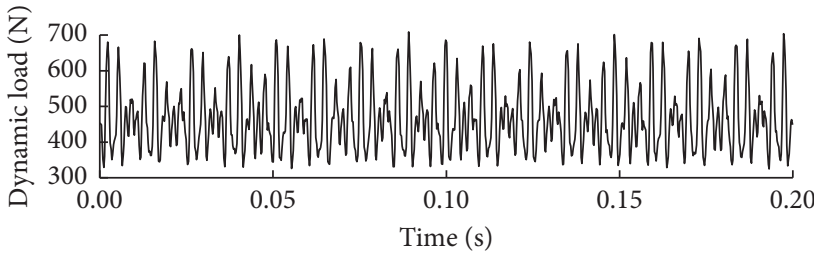

(a)

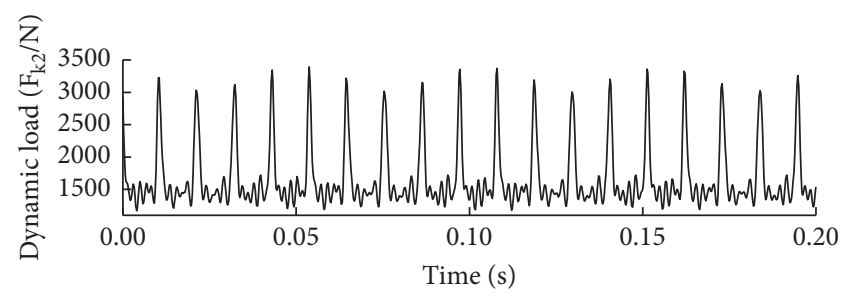

(c)

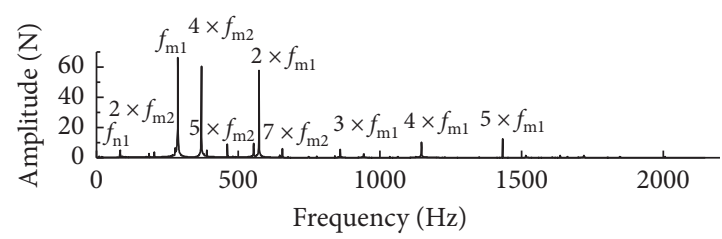

(b)

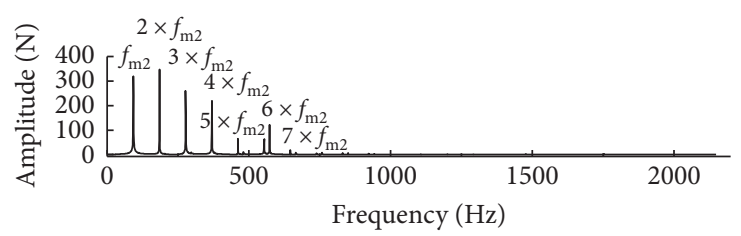

(d)

Figure 13: Dynamic load of the two-stage gear transmission system with stiff shaft. Dynamic load time history of (a) the first gear and (c) the second gear. Dynamic load spectrum history of (b) the first gear and (d) the second gear.

decreases, and the vibration response frequency composition increases under the influence of the transmission shaft flexibility. This is because the shaft's flexibility can absorb energy and decreases the transmission of vibration of the gear system. The result is consistent with the analysis in the previous work [15].

6.2. The Effect of Bearing Time-Varying Stiffness. The curves in Figures 14 and 15 compare the radial force response of the shaft 2-bearing coupled node of the system with constant bearing stiffness and TVMS in the time domain and frequency domain. It is found that considering BTVS, there is a bearing passing frequency $\left(f_{\mathrm{b} 2}\right)$ component at the low frequency. On the other hand, the introduction of BTVS has little effect on the gear dynamic response. This is because gear meshing frequency and its harmonics play a dominant role in response. $f_{\mathrm{b} 2}$ has a very small influence compared with that. The static stiffness of the bearing has a significant influence on the dynamic response of the gear system, which is consistent with the conclusions of Cao et al. [33].

\section{Experimental Study on Dynamic Characteristics}

The experiment uses the test bench of the two-stage gear transmission system made by SQI to analyze the dynamic characteristics and collect the time-domain signals of radial acceleration at the end-cap position of the bearing, as shown in Figure 16(a). Meanwhile, the two-stage gear transmission system has consistent parameters with the built model. The acceleration sensor 608A11 is placed in the gearbox. The measuring points are shown in Figure 16(b). Then, collection card DT9837 is used to output and analyze the vibration signals measured. 


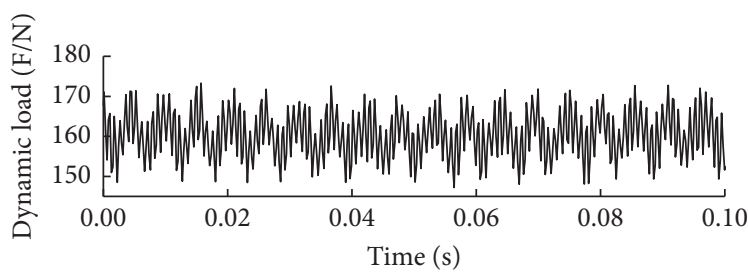

(a)

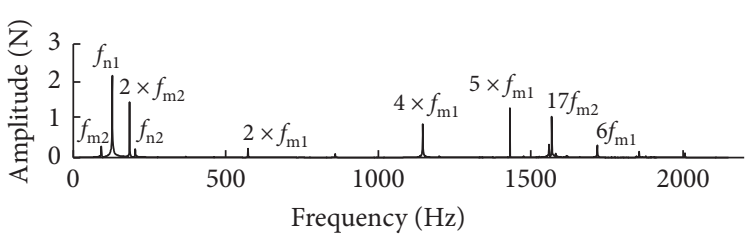

(b)

FIgURE 14: Bearing force with constant stiffness. (a) Dynamic load time history. (b) Dynamic load spectrum.

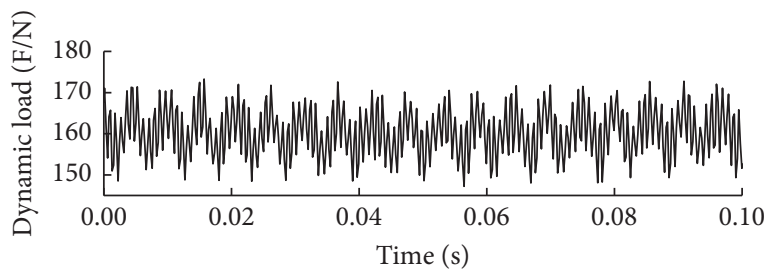

(a)

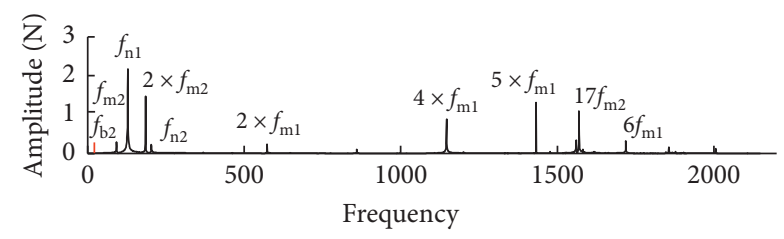

(b)

Figure 15: Bearing force with BTVS. (a) Dynamic load time history. (b) Dynamic load spectrum.

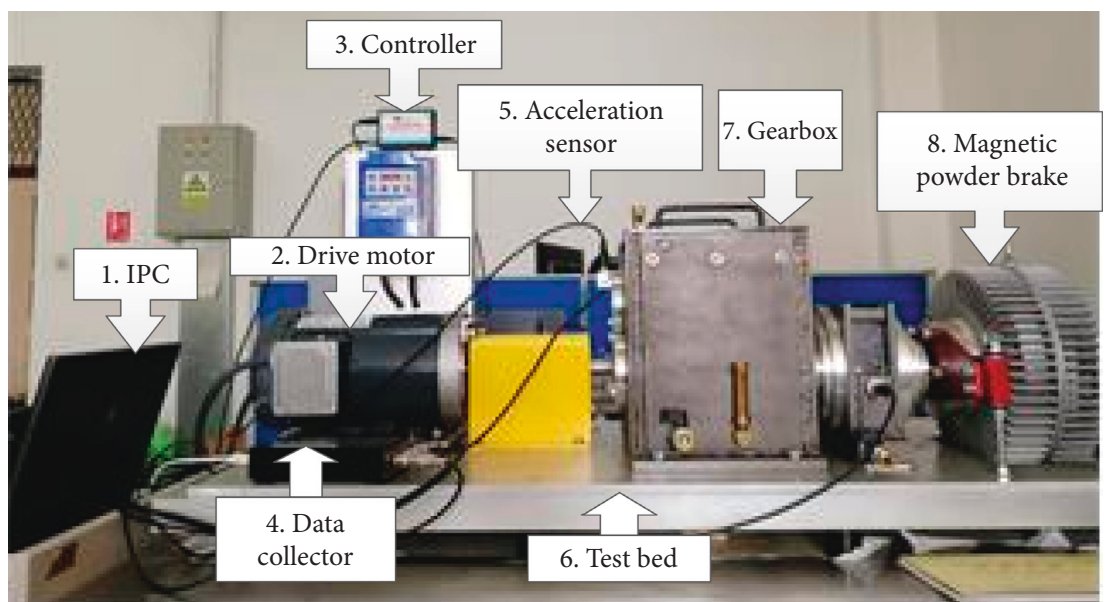

(a)

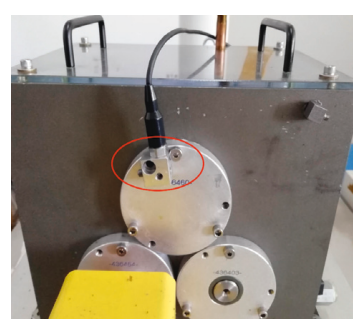

(b)

Figure 16: Test bench. (a) Transmission test-bed. (b) Measuring points.

The experiment was done to collect the time-domain signals of radial acceleration at the end-cap position of the bearing under an input speed of $960 \mathrm{rpm}$ and constant load of $10 \mathrm{~N} \cdot \mathrm{m}$ with sampling frequency of $10 \mathrm{kHz}$. Then, the frequency-domain was obtained using Fourier transform, as shown in Figure 17. The figure shows that the major frequency composition includes $f_{\mathrm{m} 1}$ and $f_{\mathrm{m} 2}$ and their harmonics. In addition, at low-frequency stage, there was a passing frequency composition $\left(f_{b}\right)$ of the bearing.

The vibration response of radial acceleration at the endcap position of the bearing is simulated as shown in Figure 18 , where $f_{\mathrm{m} 1}$ is $576 \mathrm{~Hz}, f_{\mathrm{m} 2}$ is $186 \mathrm{~Hz}\left(f_{\mathrm{m} 1}=\left(w_{1} \times\right.\right.$ $\left.Z_{\mathrm{P} 1}\right) / 2 \pi$, and $\left.f_{\mathrm{m} 2}=\left(\left(w_{1} \times Z_{\mathrm{P} 1}\right) /\left(2 \pi \times Z_{\mathrm{g} 1}\right)\right) Z_{p 2}\right)$.

It is clearly seen from Figure 18 that only at a few moments there is little shock and vibration. The vibration response signals are relatively stable. The node displacement acceleration has periodic changes. Moreover, the major frequency composition includes the passing frequency of bearing $\left(f_{\mathrm{b}}\right)$ at the low frequency because of the BTVS of bearing. In addition, the peak amplitudes of $f_{\mathrm{m} 1}$ and its harmonics and the amplitude of $2 f_{\mathrm{m} 1}(1152 \mathrm{~Hz})$ are large. This is because $2 f_{\mathrm{m} 1}$ is basically the same as the fifth-order natural frequency of the system, which increases the vibration energy of the system. The $f_{\mathrm{m} 2}$ and its doubling frequency also show vibration peaks. The harmonic $(1299 \mathrm{~Hz})$ is basically similar to the natural frequency of the sixth order of the system, so the vibration is the strongest here. There are obvious sidebands modulated by $f_{\mathrm{b}}$ and its harmonics. The low-order natural frequency of the system is listed in Table 4.

Furthermore, $f_{\mathrm{nb}}$ was also an excitation component in the experimental results, as shown in Figure 17(b). There is no such response for the simulation result because there are no basic dynamic characteristics of the test-bench. In 


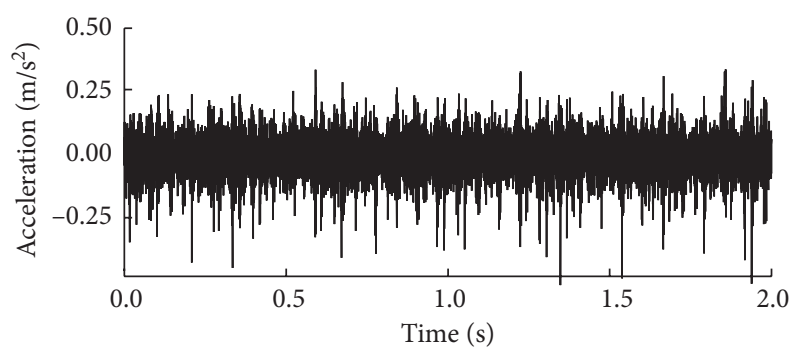

(a)

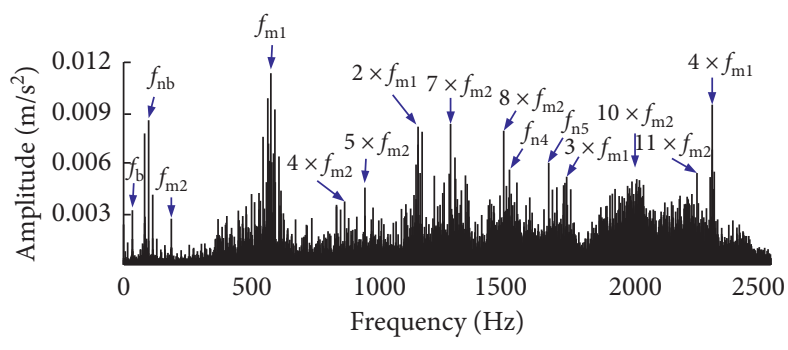

(b)

Figure 17: Time- and frequency-domain diagrams of the experimental analysis. (a) Time-domain history of acceleration. (b) Acceleration spectrum.

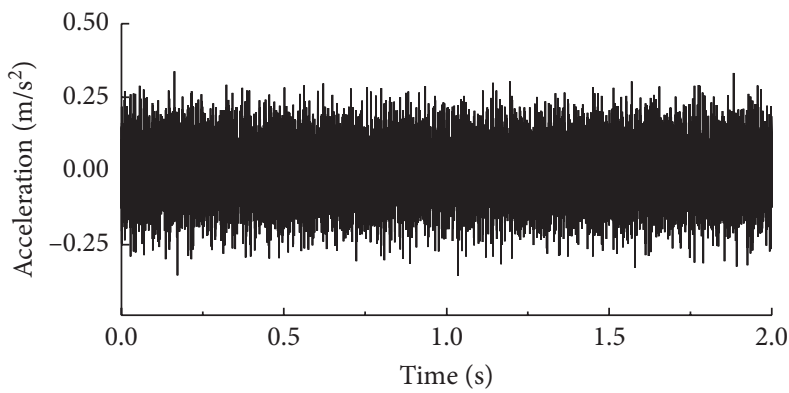

(a)

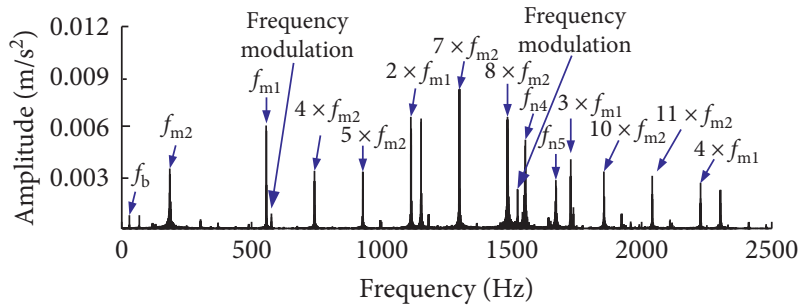

(b)

Figure 18: Time- and frequency-domain diagrams of the simulation analysis. (a) Time-domain history of acceleration. (b) Acceleration spectrum.

contrast, the gear system is at the test bench in the test. In the meantime, the natural frequency of the test bench is found to be $f_{\mathrm{nb}}$ through beat test.

When the torque is constant, the accelerations of the measuring point in the radial direction vary with the growth of speed, as shown in Figure 19. It is obvious that the two curves both have two resonance peaks of A and B. Peak A is for an input speed of $1700 \mathrm{rpm}$, where the $2 f_{\mathrm{m} 2}$ is near the natural frequency of the third order $(1055 \mathrm{~Hz})$, so that the system has a strong vibration. Peak B is for an input speed of $2200 \mathrm{rpm}$, where $f_{\mathrm{m} 1}$ and $2 f_{\mathrm{m} 1}$ are near the natural frequency of orders six and eight $(1230 / 2875 \mathrm{~Hz})$, and the tripling frequency $(1270 \mathrm{~Hz})$ of the secondary transmission system is basically the same as the natural frequency of the sixth order, so that the system shows resonance peaks. It should be noted that the amplitude of the acceleration increases significantly after passing the resonance rotational speed area, and the acceleration has a stable change along with the rotating speed. The acceleration of the simulation calculation has no big difference from that of experiment. The two curves are basically identical.

Figure 19 shows that there remains a difference between the theoretical and test results. This could because the model applies Rayleigh damping. However, the vibration mode of the system is different with the changing speed. There are different mode shapes. For the further study, modal damping can be used in future research. Meanwhile, the coupling of air and lubricating oil also influence the system's acceleration and cause error between the simulation and test [34].

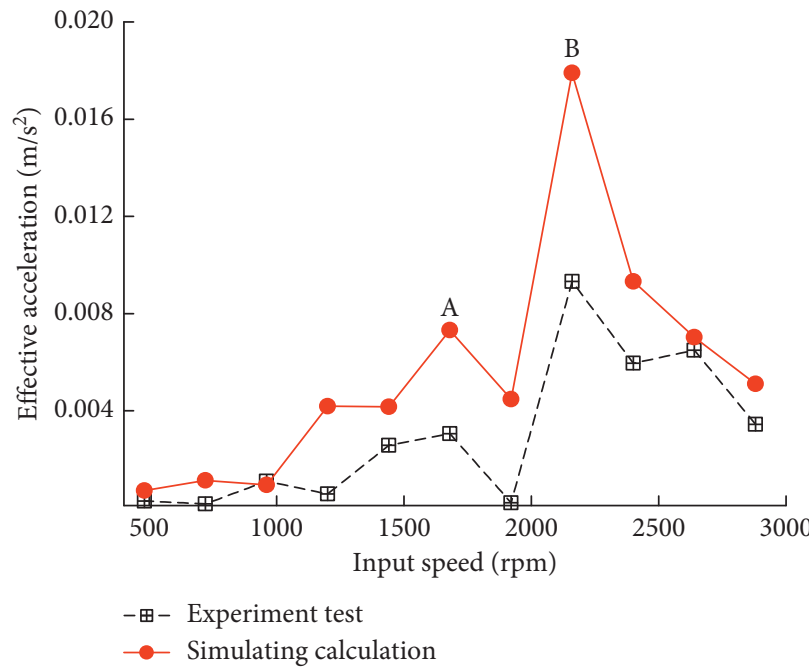

FIGURE 19: Comparison of simulation and experiment results.

\section{Effect of Shaft Stiffness on System}

8.1. Shaft Static Deformation Analysis. In order to study the influence of the shaft stiffness on the static deformation of the shaft, the static deformation of the transmission shaft was calculated with the transmission shaft stiffness $k_{\mathrm{sh}}$ being $0.25 \times k_{\mathrm{sh}}, \quad 0.5 \times k_{\mathrm{sh}}, \quad 1.0 \times k_{\mathrm{sh}}, \quad 2.0 \times k_{\mathrm{sh}}, \quad 4.0 \times k_{\mathrm{sh}}, \quad$ and $10.0 \times k_{\text {sh }}$ (initial stiffness is $k_{\text {sh }}$ ). Figure 20(a) shows that the changing law of the shaft static deformation is similar under the different shaft stiffness. At the shaft-gear coupled node, 


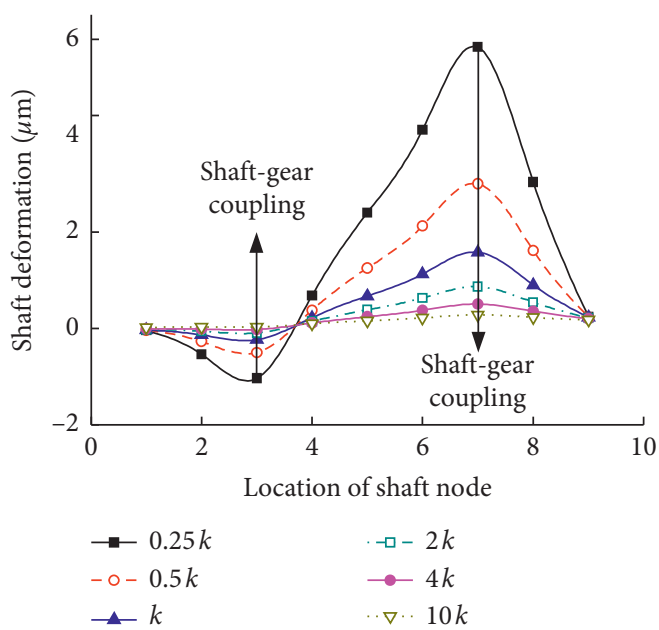

(a)

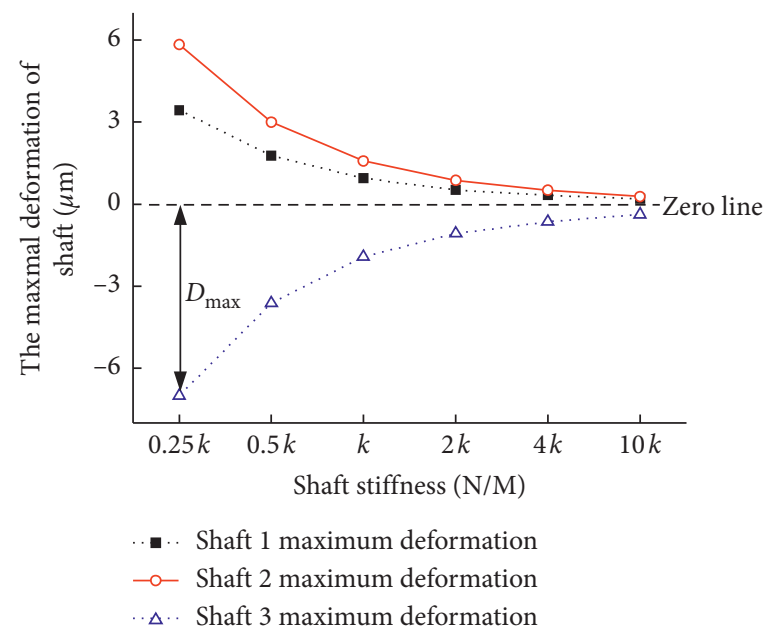

(b)

FIGURE 20: Effect of stiffness of transmission shaft on its static deformation.

the deformation is the most obvious. Moreover, along with the increase of the stiffness of the shaft, the deformation of the shaft at the same node becomes smaller and smaller. It is assumed that the deformation of the transmission shaft is $D_{\max }$, showing that the value of deformation of each shaft also gradually decreases along with the increase of the stiffness of the transmission shaft through simulation. This is shown in Figure 20(b).

\subsection{Effect of the Flexibility of Transmission Shaft on Natural} Frequency and Mode Shape. The stiffness of the transmission shaft can affect the bearing loads, natural characteristics, and vibration noises of the reducer. The natural frequency and mode shape of the system are obtained with the stiffness of transmission shaft $k_{\mathrm{sh}}$ being $0.25 \times k_{\mathrm{sh}}, 0.5 \times k_{\mathrm{sh}}, 1.0 \times k_{\mathrm{sh}}$, $2.0 \times k_{\mathrm{sh}}, 4.0 \times k_{\mathrm{sh}}$, and $10.0 \times k_{\mathrm{sh}}$. Along with the increase of transmission stiffness, the natural frequencies of the system at each order also increase from equation (15). For instance, with a stiffness of $0.25 \times k$, the natural frequency of the first order is $64.19 \mathrm{~Hz}$, and with a stiffness of $0.5 \times k$, the natural frequency of the second order is $90.68 \mathrm{~Hz}$, increased by $41.23 \%$.

If the effect of the shaft stiffness on the system mode shape is considered, the curve of the first mode shapes of shaft 2 with different stiffness $\left(k_{\mathrm{sh}}=0.25 \times k_{\mathrm{sh}}, k=10 \times k_{\mathrm{sh}}\right)$ is shown in Figure 21. It is shown that the transmission shaft has the mode shape of translational and torsional coupling vibration. The vector of torsional mode shape is far more than the translational ones. Thus, torsional mode shape is a dominant vibration, which is the main cause of system vibration. So, it necessary to analyze the dominant vibration under different mode orders.

Meanwhile, it is found that the change of the shaft stiffness affects the dominant vibration of the system at orders $4,5,15,19$, and 20 with simulation. The changes are shown in Table 5.

Table 5 shows that different transmission shaft stiffness values can result in changes of dominant mode shapes of the gear system. For instance, if the shaft stiffnesses are $0.5 k_{\mathrm{sh}}$ and $0.25 k_{\mathrm{sh}}$, the dominant mode shape of the coupling system will change from torsional vibration to translation vibration compared with the shaft stiffness of others. In a general way, the torsional vibration occurs more easily in the work time. So, the decrease of stiffness of the transmission shaft can effectively reduce the probability of resonance. The analytical results can provide some guidance for engineering application.

8.3. Bearing Dynamic Load Analysis. In the spur gear system, the distance between two bearings is different, leading to different dynamic loads on bearing and vibration response of gear shaft-bearing system under imbalanced excitation. In addition to this, the flexibility of shaft can absorb energy and make an influence on vibration transmission, which also affects the load distribution of both ends of the bearing.

The effects of shaft stiffness on bearing load distribution are studied in this part. NEM is used to solve the model under the input speed of $500 \mathrm{rpm}$ and the load of $100 \mathrm{~N} \cdot \mathrm{m}$. The average radial dynamic loads at $a$ and $b$ ends of bearing of each shaft are obtained through simulation. The difference between the force of two bearing ends is defined as

$$
\Delta f_{\mathrm{p}}=\left|F_{\mathrm{pxa}}-F_{\mathrm{pxb}}\right|,
$$

where $F_{\mathrm{pxa}}$ and $F_{\mathrm{pxb}}$ denote the average radial forces at a and $b$ ends of bearing, respectively.

It shows that the change of stiffness of transmission shaft can affect the distribution of bearing force of $a$ and $b$ shafts at input end, middle end, and output end from Figure 22. Along with the increase of transmission shaft's stiffness, the force of $a$ and $b$ ends tends to be balanced, so if the transmission shaft has greater flexibility, the force difference at two ends will be greater and deflection and warping of shaft can occur in an easier way. To some extent, increasing the stiffness of the shaft can add the fatigue life of the bearing. 


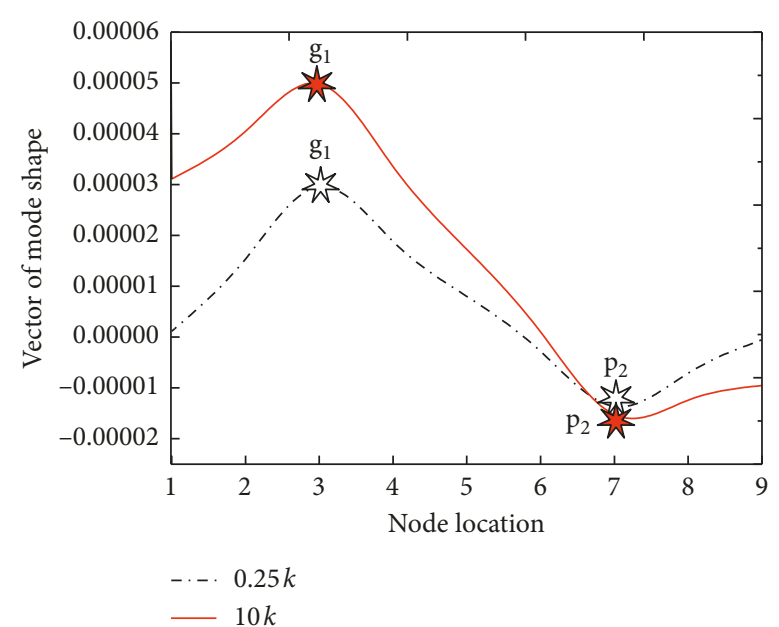

(a)

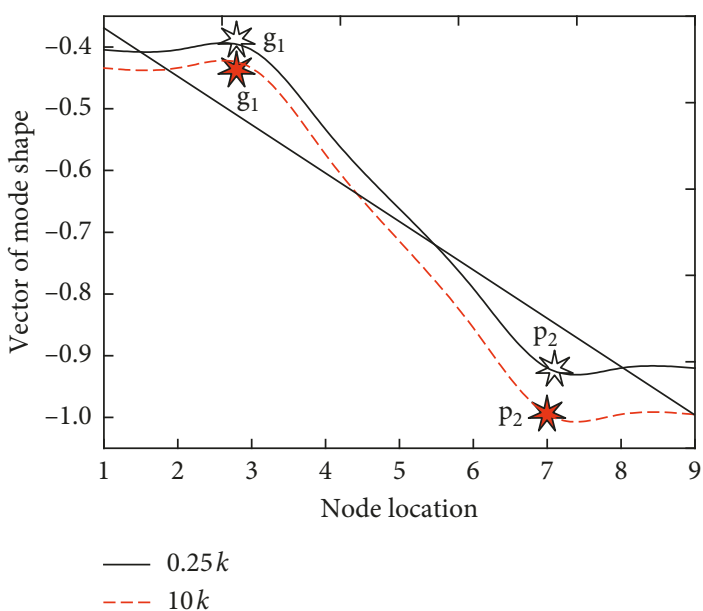

(b)

FIgURE 21: The effect of shaft stiffness on mode shape. (a) First-order translation mode. (b) First-order torsional mode.

TABLE 5: Change of dominant vibration at different stiffness values.

\begin{tabular}{|c|c|c|c|c|c|c|c|c|c|c|}
\hline Order & $\begin{array}{l}\text { Mode type } \\
\left(0.25 k_{\mathrm{sh}}\right)\end{array}$ & Position & $\begin{array}{l}\text { Mode type } \\
\left(0.5 k_{\mathrm{sh}}\right)\end{array}$ & Position & $\begin{array}{l}\text { Mode type } \\
\left(k_{\mathrm{sh}}\right)\end{array}$ & Position & $\begin{array}{l}\text { Mode type } \\
\left(2 k_{\mathrm{sh}}\right)\end{array}$ & Position & $\begin{array}{c}\text { Mode type }\left(4 k_{\mathrm{sh}} /\right. \\
\left.10 k_{\mathrm{sh}}\right)\end{array}$ & Position \\
\hline W4 & Lateral & g & Lateral & g2 & TV & $S$ & Torsional & Sha & Torsional & Shaft $_{\text {in }}$ \\
\hline W5 & Torsic & 0 & Torsional & II & Latera & & Lateral & $\mathrm{g} 2$ & Lateral & g2 \\
\hline W15 & Torsional & Shaft $_{\text {in }}$ & Torsional & Shaft $_{\text {in }}$ & Lateral & Shaft $_{\text {in }}$ & Lateral & Shaft $_{\text {in }}$ & Lateral & Shaft $_{\text {in }}$ \\
\hline W19 & Torsional & Shaft $_{\text {out }}$ & Lateral & Shaft $_{\text {in }}$ & Lateral & Shaft $_{\text {in }}$ & Lateral & Shaft $_{\text {in }}$ & Lateral & Shaft $_{\text {in }}$ \\
\hline W20 & Torsional & Shaft $_{\text {in }}$ & Torsional & Shaft $_{\text {in }}$ & Torsional & Shaft $_{\text {in }}$ & Torsional & Shaft $_{\text {in }}$ & Lateral & Shaft $_{\text {in }}$ \\
\hline
\end{tabular}

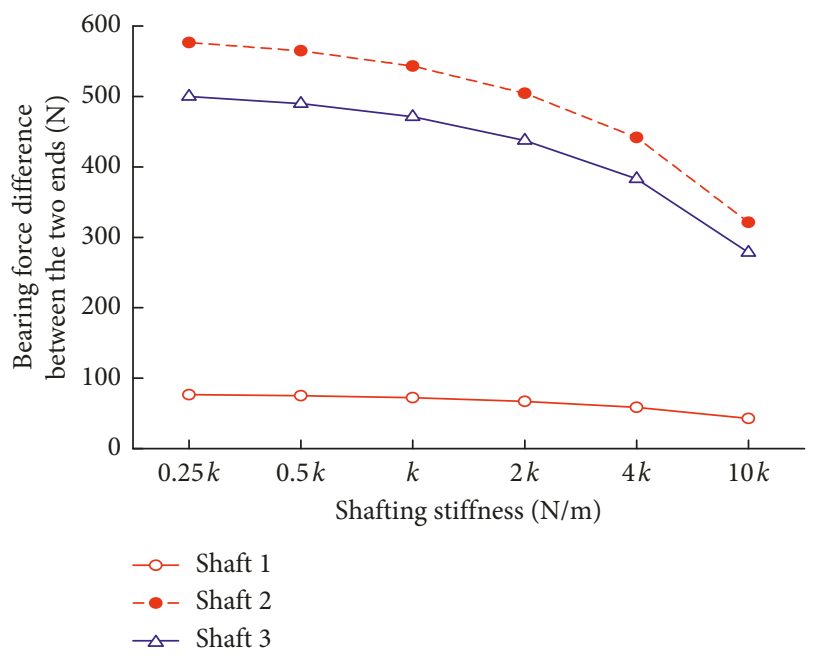

FIGURE 22: Effect of stiffness of transmission shaft on the imbalanced force at two ends of bearing.

8.4. Resonance Characteristics Analysis. Though the parameter of two-stage gear transmission system is a linear problem, the dynamic response frequency composition is complicated due to the impact of TVMS and natural frequency of the system. Furthermore, different input speeds can directly affect the frequency composition of the excitation. In order to explore the effect of the input speed on the dynamic load fluctuation of the system, the change of fluctuation amplitude of the dynamic load of gear is calculated at major input speed of the reducer (500-10000 rpm) with different shaft stiffnesses, as shown in Figure 23.

The figure shows that, along with the increase of input speed, the dynamic load amplitude has great changes. At the initial shaft stiffness $\left(k_{\mathrm{sh}}\right)$, if the input speed is $668 \mathrm{rpm}$, $1671 \mathrm{rpm}$, and $2244 \mathrm{rpm}$, the two-stage gear dynamic load has vibration peaks. This is because, at an input speed of $668 \mathrm{rpm}$, the first-stage four-time harmonic frequency component $\left(4 f_{\mathrm{m} 1}\right)$ is near the natural frequency of the fourth-order, and the system has greater vibration. At an input speed of $1671 \mathrm{rpm}$, the second-stage 10-time harmonic frequency component $\left(10 f_{\mathrm{m} 2}\right)$ is near to the natural frequency of eighth order, so that the system has greater vibration energy. If the input speed increases and the input speed is $6493 \mathrm{rpm}$, the $2 f_{\mathrm{m} 2}(1250 \mathrm{~Hz})$ is not very different from the natural frequency of the third order and the torsional vibration of order three appears, leading to resonance of the system. However, the dynamic load amplitude value greatly decreases after passing the resonance area. In the same time, at an input speed of 7400 and $8498 \mathrm{rpm}$, the firststage gear has a great response, because the $2 f_{\mathrm{m} 2}$ at such an input speed is consistent with the natural frequency of orders 14 and 16, making the first shaft vibrate greatly, as shown in Figure 23(a). The frequency component of the peak is listed in Table 6 .

With the increase of shaft stiffness, the peak value of the dynamic load of the two-stage gear increases greatly as well. For instance, if the input speed increases to $4.0 \times k_{\mathrm{sh}}$, the 


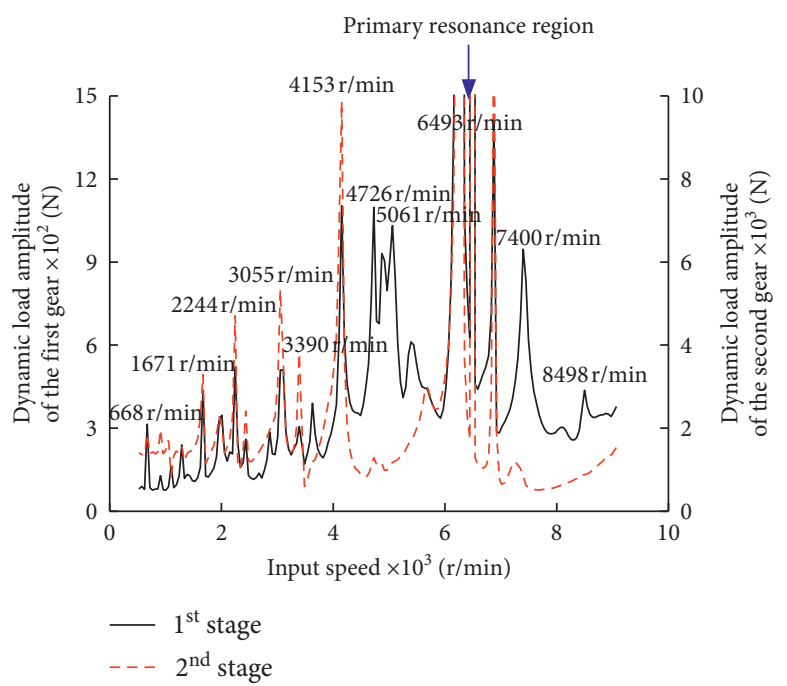

(a)

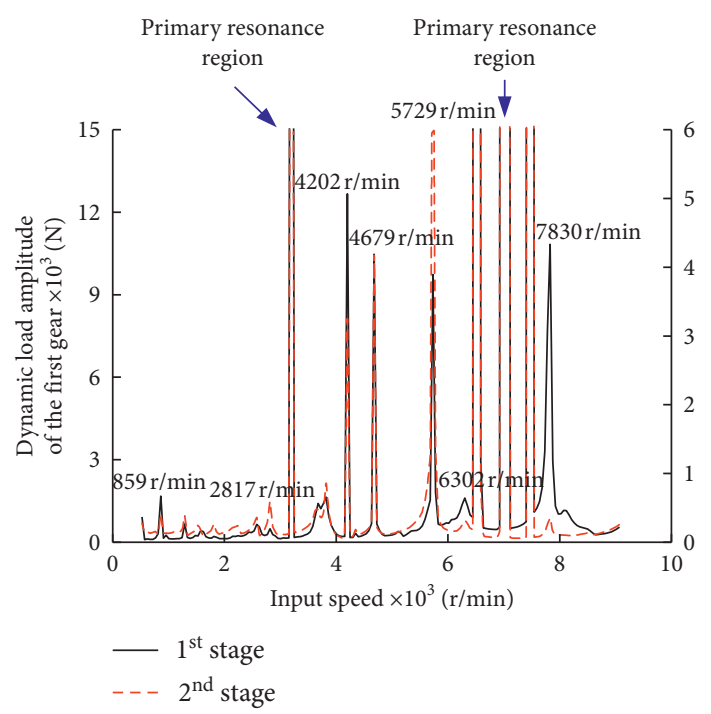

(c)

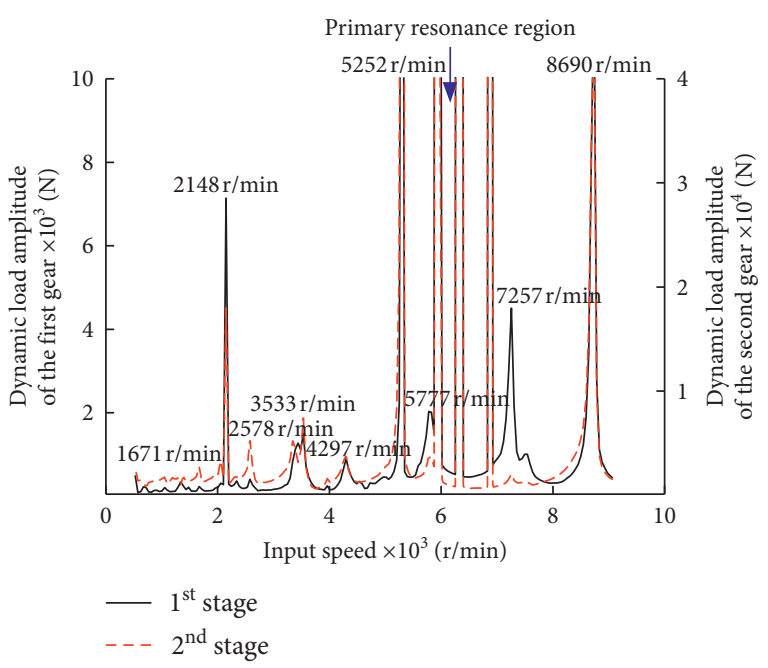

(b)

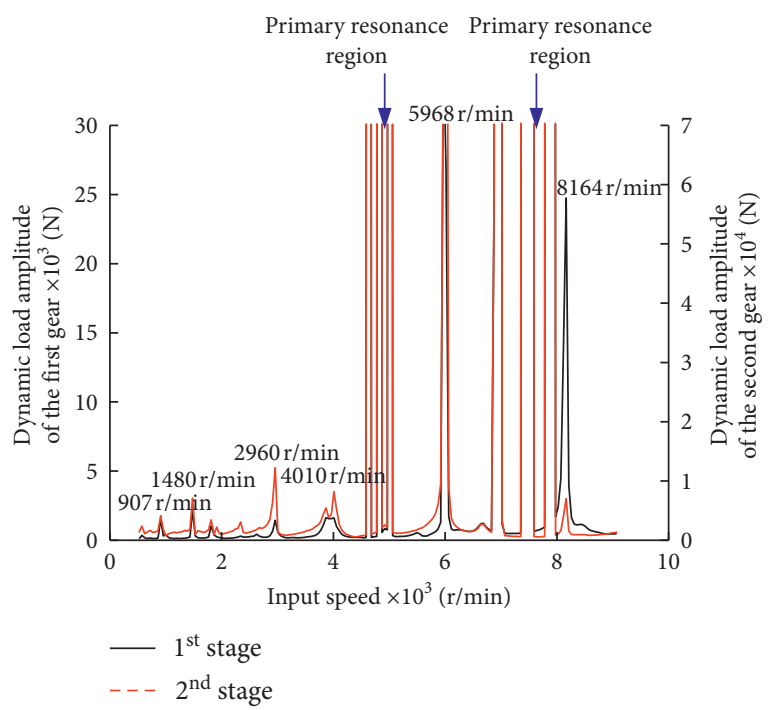

(d)

FIgURE 23: The effect of shaft stiffness on dynamic load amplitude: (a) $k$, (b) $4 k$, (c) $6 k$, and (d) $8 k$.

Table 6: Positions of fluctuating amplitudes of dynamic load of gear (Frequency $\mathrm{Hz}$ ).

\begin{tabular}{lccccccccccc}
\hline Input speed $(\mathrm{rpm})$ & 668 & 1671 & 2244 & 3103 & 4153 & 4726 & 5061 & 6493 & 6875 & 7400 & 8498 \\
\hline Amplitude frequency $(\mathrm{Hz})$ & 1600 & 3218 & 1729 & 7432 & 1600 & 8490 & 6061 & 3887 & 6620 & 8862 & 10178 \\
Frequency composition & $4 f_{\mathrm{m} 1}$ & $10 f_{\mathrm{m} 2}$ & $4 f_{\mathrm{m} 2}$ & $4 f_{\mathrm{m} 1}$ & $2 f_{\mathrm{m} 2}$ & $3 f_{\mathrm{m} 1}$ & $2 f_{\mathrm{m} 1}$ & $f_{\mathrm{m} 2}$ & $5 f_{\mathrm{m} 2}$ & $2 f_{\mathrm{m} 1}$ & $2 f_{\mathrm{m} 1}$ \\
\hline
\end{tabular}

system has resonance at the torsional direction at speeds of 5252, 6302, and $6350 \mathrm{rpm}$, and the gear's dynamic load has sharp changes at the peak amplitudes, as shown in Figure 23(b). It was shown in Section 8.2 that, with the stiffness of transmission shaft $k_{\mathrm{sh}}$ increasing to $2 k_{\mathrm{sh}}, 4 k_{\mathrm{sh}}$, and $10 k_{\mathrm{sh}}$, the fourth-order vibration mode also changes. The system transforms from torsional vibration to bending vibration and has fewer vibration peak points. When the stiffness of the transmission shaft increases, the system's natural frequency also changes and the torsional mode shape of the system is triggered to form many resonance areas, increasing the possibility of system resonance. Therefore, reasonable design of the stiffness of the transmission shaft can effectively avoid the production of the torsional resonance of the system. Thus, the design and analysis of the gear shaft cannot neglect the effect of the flexibility of the shaft.

\section{Conclusion}

In this study, a novel modeling method for the coupling vibration analysis of a two-stage spur gear transmission system is presented with FEM. The model considered the 
TVMS, BTVS, and two-stage phase relationship and solved the system dynamic characteristics with the NIM. Meanwhile, the influence of shaft stiffness change was investigated. The primary conclusions are as follows:

(1) With the influence of bearing time-varying stiffness, there is a bearing passing frequency component $f_{\mathrm{b}}$ in low-frequency location. Moreover, compared with a rigid shaft model, because the flexibility of the transmission shaft can absorb and isolate part of the energy, the dynamic load decreased, and the number of frequency components of the vibration response also decreased.

(2) Considering the flexibility of the transmission shaft and the TVMS of the bearing and gear effectively, the frequency component's distribution in the simulation is basically consistent with the test. Additionally, the effectiveness of the calculation method was verified comparing the simulation data with the experimental ones under the condition of increasing speed.

(3) At the initial shaft stiffness $\left(k_{\mathrm{sh}}\right)$, if the input speed is $668 \mathrm{rpm}, 1671 \mathrm{rpm}$, and $2244 \mathrm{rpm}$, the two-stage gear dynamic loads show amplitude peaks. With the increase of the stiffness of the transmission shaft, the dominant mode shape (torsional mode shapes) of the system increases. Meanwhile, the dominant vibration areas appear divided, and the total amplitude value of the system also increases.

(4) With the increase of the stiffness of transmission shaft, the forces at the two ends of the bearing become more consistent. This can provide a theoretical basis for the noise prediction of the gearbox.

\section{Data Availability}

The data used to support the findings of this study are included within the article.

\section{Conflicts of Interest}

The authors declare that they have no conflicts of interest.

\section{Acknowledgments}

The authors thank Xinjiang University for providing good facilities. The study was supported by the Chinese National Natural Science Foundation (51665054) and Opening Foundation of State Key Laboratory of Mechanical Transmissions (SKLMT-KFKT-201714).

\section{References}

[1] T. Ouyang, G. Huang, J. Chen, B. Gao, and N. Chen, "Investigation of lubricating and dynamic performances for high-speed spur gear based on tribo-dynamic theory," Tribology International, vol. 136, no. 8, pp. 421-431, 2019.

[2] H. Liu, C. Zhang, and C. Wang, "Transverse-swing-torsional coupling of two-stage involute gear transmission system.
Nonlinear dynamics modeling and experimental verification," Vibration and Shock, vol. 36, no. 15, pp. 124-132, 2017.

[3] Y. Pandya and A. Parey, "Simulation of crack propagation in spur gear tooth for different gear parameter and its influence on mesh stiffness," Engineering Failure Analysis, vol. 30, pp. 124-137, 2013.

[4] W. Jing, A.-Q. Zhang, D. Qin et al., "A coupling dynamics analysis method for a multistage planetary gear system," Mechanism and Machine Theory, vol. 110, pp. 27-49, 2017.

[5] K. Umezawa, H. Houjoh, and H. Yoshimura, "The effect of shaft stiffness on the gear vibration," Bulletin of the JSME, vol. 54, no. 499, pp. 699-705, 1987.

[6] R. Guilbault, M. S. Lalonde, and M. Thomas, "Nonlinear damping calculation in cylindrical gear dynamic modeling," Journal of Sound and Vibration, vol. 331, no. 9, pp. 2110-2128, 2012.

[7] F. Ren, D.-T. Qin, and X.-L. Wu, "Research on the dynamics of the double helical gear transmission," Applied Mechanics and Materials, vol. 456, no. 15, pp. 256-259, 2013.

[8] S. Wu, M. J. Zuo, and A. Parey, "Simulation of spur gear dynamics and estimation of fault growth," Journal of Sound and Vibration, vol. 317, no. 3-5, pp. 608-624, 2008.

[9] W. Jing, A.-Q. Zhang, G.-Q. Wang et al., "A study of nonlinear excitation modeling of helical gears with modification: theoretical analysis and experiments," Mechanism and Machine Theory, vol. 128, pp. 314-335, 2018.

[10] Z. Wang, L. Zhang, Y.-Q. Luo, and C.-Z. Chen, "Dynamic model of spur gear pair with modulation internal excitation," International Journal of Rotating Machinery, vol. 2017, Article ID 1264904, 8 pages, 2017.

[11] B. Neriya and T. S. Sankar, "The coupled torsional-flexural vibration of a geared shaft system using finite element method," The Shock and Vibration Bulletin, vol. 55, no. 3, pp. 13-25, 1985.

[12] S. V. Modak, T. K. Kundra, and B. C. Nakra, "Use of an updated finite element model for dynamic design," $\mathrm{Me}$ chanical Systems and Signal Processing, vol. 16, no. 2-3, pp. 303-322, 2002.

[13] H. N. ÖzgÜven and Z. L. Özkan, "Whirl speeds and unbalance response of multi bearing rotors using finite elements," Journal of Vibration, Acoustics, Stress and Reliability in Design, vol. 106, no. 1, pp. 72-79, 1984.

[14] T. Ouyang, Z. Su, S. Li, G. Huang, and N. Chen, "Experimental and numerical investigations on dynamic characteristics of gear-roller-bearing system," Mechanism and Machine Theory, vol. 140, no. 10, pp. 730-746, 2019.

[15] M. Kubur, A. Kahraman, D. M. Zini, and K. Kienzle, "Dynamic analysisof a multi-shaft helical gear transmission by finite elements: model and experiment," Journal of Vibration and Acoustics, vol. 126, no. 3, pp. 398-406, 2004.

[16] Q.-L. Jiang, D.-Z. Wu, and S.-G. Tan, "Development and application of a model for coupling gearedrotors system," Journal of Vibration Engineering, vol. 23, no. 3, pp. 254-259, 2010.

[17] Y. Guo, T. Eritenel, T. M. Ericson, and R. G. Parker, "Vibroacoustic propagation of gear dynamics in a gear-bearinghousing system," Journal of Sound and Vibration, vol. 333, no. 22, pp. 5762-5785, 2014.

[18] H. Ma, X. Pang, R. Feng, and B. Wen, "Evaluation of optimum profile modification curves of profile shifted spur gears based on vibration responses," Mechanical Systems and Signal Processing, vol. 70-71, pp. 1131-1149, 2016.

[19] L. Qian, J.-Y. Tang, S.-Y. Chen, and Y. Liu, "Dynamic modeling of a one-stage gear system by finite element method 
and the dynamic analysis in high speed," Journal of Mechanical Engineering, vol. 52, no. 17, pp. 155-161, 2016.

[20] S. Ankur, C. Manoj, and P. Anand, "Measurement of FRFs of coupled geared rotor system and the development of an accurate finite element model," Mechanism and Machine Theory, vol. 123, no. 1, pp. 66-75, 2018.

[21] J. Wang, Numerical and Experimental Analysis of Spur Gears in Mesh, Curtain University of Technology, Bentley, Australia, 2003.

[22] A. Tatar, C. W. Schwingshackl, and M. I. Friswell, "Dynamic behaviour of three-dimensional planetary geared rotor systems," Mechanism and Machine Theory, vol. 134, pp. 39-56, 2019.

[23] J. Li, Theoretical Study of Space Beam Element and its Application in Bridges, Changsha University of Science and Technology, Changsha, China, 2014.

[24] C.-B. Hu, Y.-G. Wang, and D.-S. Ling, "Effect of Rayleigh damping physical essence and parameters on dynamic response," Journal of Zhe Jiang University (Engineering Science), vol. 51, no. 6, pp. 1196-1203, 2017.

[25] Z.-Z. Qiao, J.-X. Zhou, and X.-F. Zhang, "Research on finite element modeling method of two-stage spur gear transmission system under multi-source time-varying excitation," Journal of Vibration and Shock, vol. 38, no. 15, pp. 182-189, 2019.

[26] R. Chen, J. Zhou, and W. Sun, "Dynamic characteristics of a planetary gear system based on contact status of the tooth surface," Journal of Mechanical Science and Technology, vol. 32, no. 1, pp. 69-80, 2018.

[27] L.-H. Chang, Z.-X. He, and G. Liu, "Finite element method for dynamic modeling of parallel shaft gear transmission system," Journal of Vibration and Shock, vol. 35, no. 20, pp. 47-53, 2016.

[28] H. Ma, R.-Z. Song, X. Pang, and B. Wen, "Fault feature analysis of a cracked gear coupled rotor system," Mathematical Problems in Engineering, vol. 2014, Article ID 832192, 22 pages, 2014.

[29] S. L. Harris, "Dynamic load on the teeth of spur gears," Proceedings of the Institution of Mechanical Engineers, vol. 172, no. 1, pp. 87-112, 1958.

[30] Y. Yang, L.-Y. Cao, H. Li, and Y. Dai, "Nonlinear dynamic response of a spur gear pair based on the modeling of periodic mesh stiffness and static transmission error," Applied Mathematical Modelling, vol. 72, no. 6, pp. 444-469, 2019.

[31] B. Yuan, S. Chang, G. Liu, L.-H. Chang, and L. Liu, "Quasistatic analysis based on generalized loaded static transmission error and dynamic investigation of wide-faced cylindrical geared rotor systems," Mechanism and Machine Theory, vol. 134, no. 8, pp. 289-296, 2019.

[32] Y. Li, K. Ding, G.-L. He, and H. Lin, "Modulation sidebands of the vibration signal of gearbox," Journal of Mechanical Engineering, vol. 54, no. 5, pp. 105-112, 2018.

[33] H. Cao, Y.-M. Li, and Z.-J. He, "Time varying bearing stiffness and vibration response analysis of high speed rolling bearingrotor systems," Journal of Mechanical Engineering, vol. 50, no. 15, pp. 73-81, 2014.

[34] Xiaowei Cheng, Xiaohui Shi, and Quan Shi, "Study on the error wheel and experimental research of secondary gear transmission," Journal of Chongqing University of Technology (Natural Science), vol. 24, no. 11, pp. 19-24, 2010. 


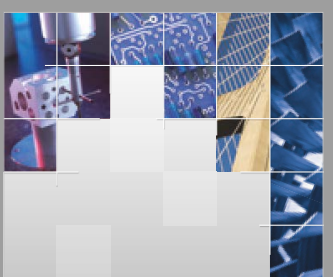

\section{Enfincering}
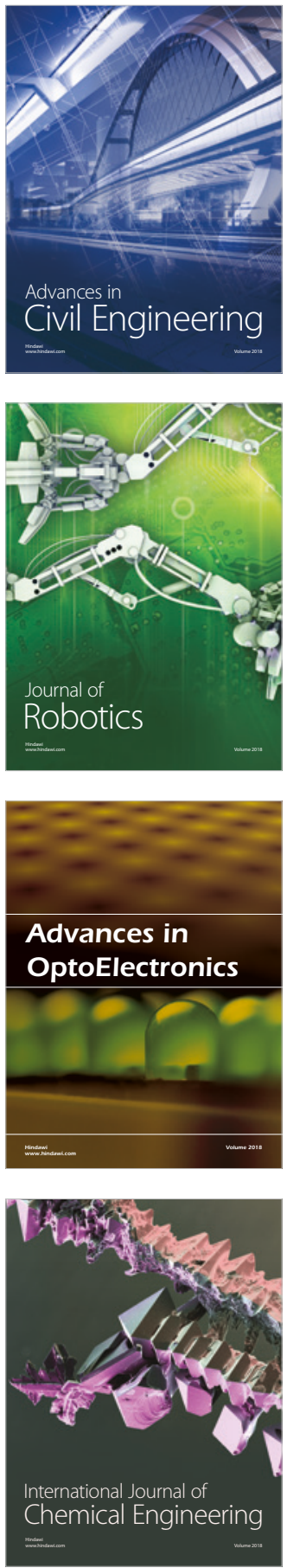

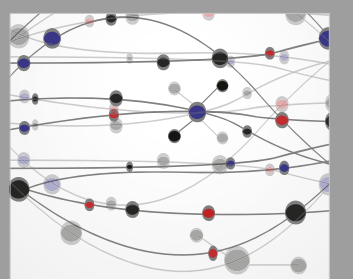

\section{Rotating \\ Machinery}

The Scientific World Journal

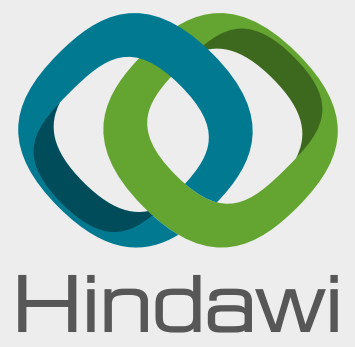

Submit your manuscripts at

www.hindawi.com
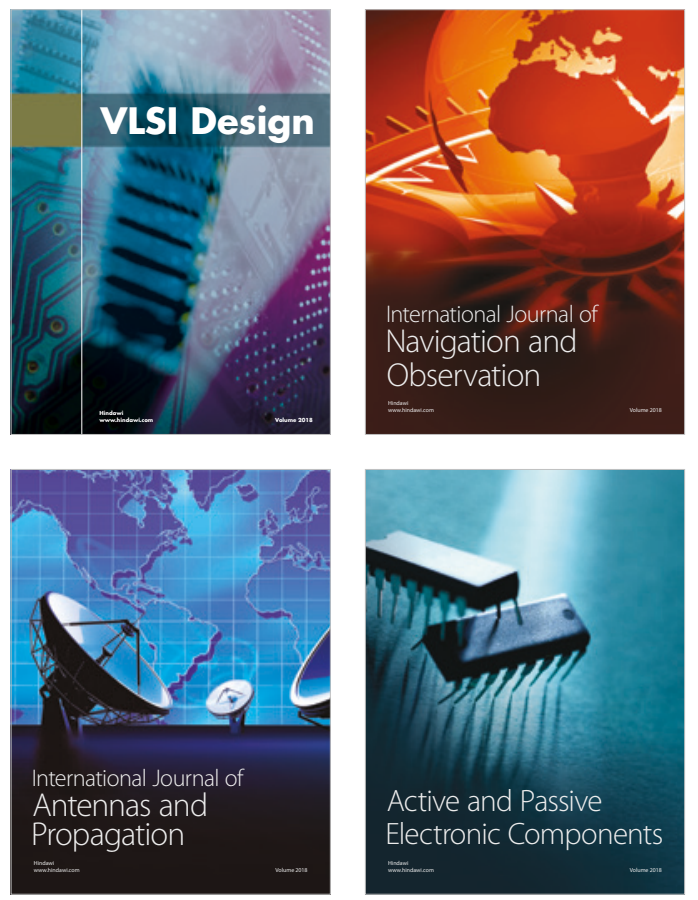
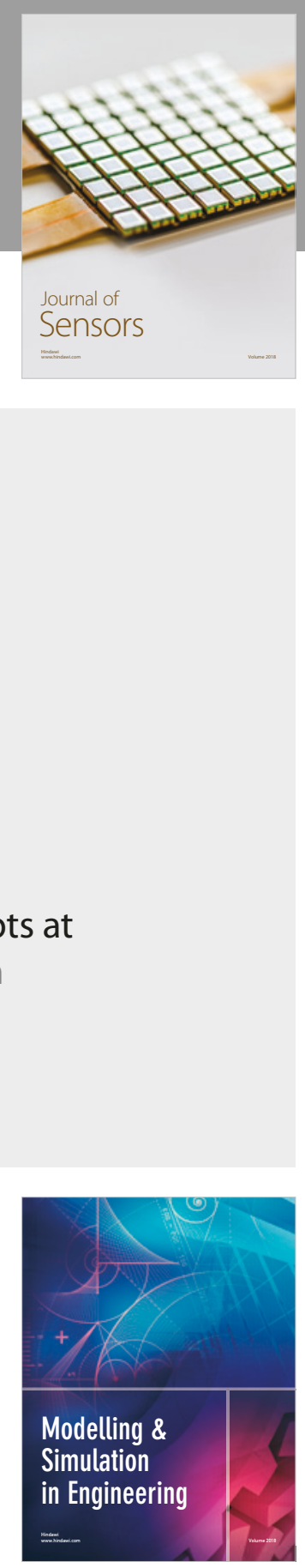

\section{Advances \\ Multimedia}
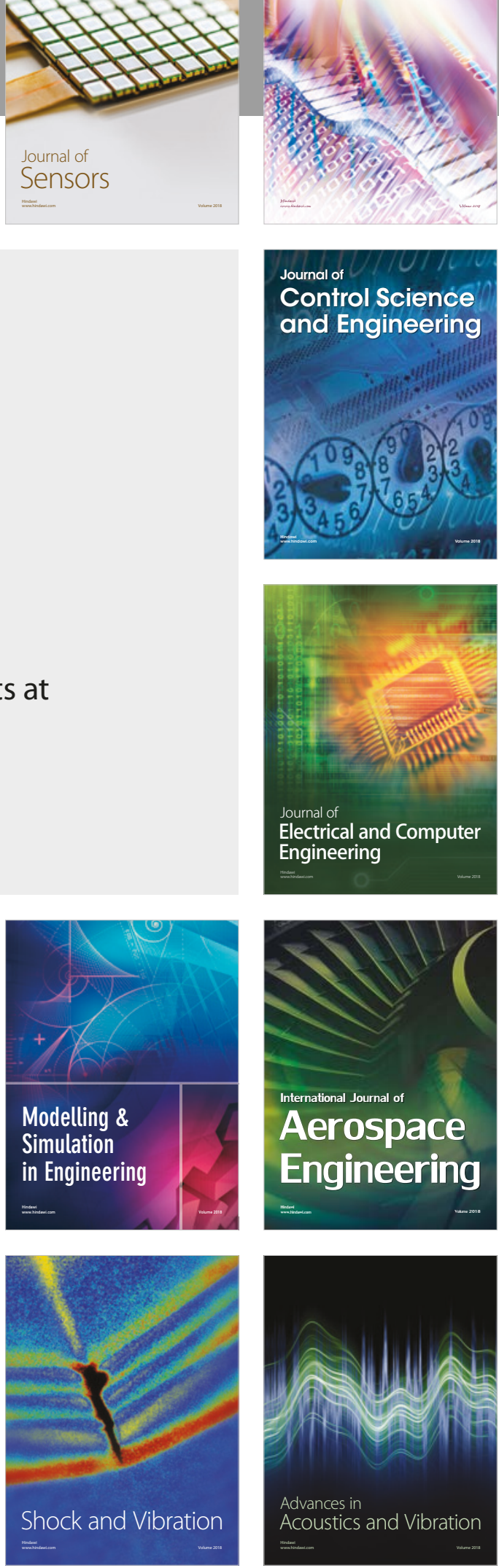